\title{
Dynamic Portfolio Selection in Gas Transmission Projects Considering Sustainable Strategic Alignment and Project Interdependencies through Value Analysis
}

\author{
Fahime Lotfian Delouyi, Seyed Hassan Ghodsypour* and Maryam Ashrafi (D)
}

check for updates

Citation: Lotfian Delouyi, F.; Ghodsypour, S.H.; Ashrafi, M. Dynamic Portfolio Selection in Gas Transmission Projects Considering Sustainable Strategic Alignment and Project Interdependencies through Value Analysis. Sustainability 2021, 13, 5584. https://doi.org/10.3390/ su13105584

Academic Editors: Alfredo del Caño Gochi, María Pilar de la Cruz López, Manuel Lara and Juan José Cartelle Barros

Received: 16 April 2021

Accepted: 11 May 2021

Published: 17 May 2021

Publisher's Note: MDPI stays neutral with regard to jurisdictional claims in published maps and institutional affiliations.

Copyright: (c) 2021 by the authors. Licensee MDPI, Basel, Switzerland. This article is an open access article distributed under the terms and conditions of the Creative Commons Attribution (CC BY) license (https:/ / creativecommons.org/licenses/by/ $4.0 /)$.
Department of Industrial Engineering and Management Systems, Amirkabir University of Technology, 350 Hafez Ave, Tehran 15916-34311, Iran; fahime.lotfian@aut.ac.ir (F.L.D.); ashrafi.mm@aut.ac.ir (M.A.)

* Correspondence: ghodsypo@aut.ac.ir; Tel.: +98-21-6454-5390

\begin{abstract}
Selecting a sustainable cross-country natural gas pipeline project portfolio plays a vital role in enhancing energy security and national self-reliance. The interdependencies between projects augment the complexity of project portfolio selection. Hence, the selection must be done with sustainable strategic alignment and adjustment of ongoing projects to determine the most suitable project portfolio. This is while they have barely been addressed simultaneously in the literature. The aim of the present study is to fill in the mentioned gap by establishing an integrated framework incorporating the organization strategies, project interdependencies, and ongoing projects in the project portfolio selection problem. This presented framework uses network mapping to visualize project interdependencies and improve the quality of the resulting decision. The decision-aid approach of Measuring Attractiveness by a Categorical Based Evaluation Technique (MACBETH) was employed to tackle multi-criteria value measurement in project portfolio selection. Applicability and validity of the proposed framework were tested using the case study of the Iranian Gas Engineering and Development Company (IGEDC). The pipeline project portfolios were analyzed on the basis of experts' opinions with regard to technical and sustainability strategic criteria (economic, environmental, and social pillars).
\end{abstract}

Keywords: natural gas pipeline; sustainable project portfolio; project interdependencies; project adjustment; multi-criteria decision analysis

\section{Introduction}

Natural gas is an eco-friendly energy source. As one of the most efficient and clean combustion energy alternatives, natural gas has a superior position in the transportation sector, for electricity generation, and as a domestic fuel [1,2]. Natural gas is expected to replace oil in the transportation sector of Iran, promote energy security, and address the climate change challenges [3]. Pipelines are known as the most practical, economically effective, and environmentally friendly channels for natural gas transportation over long distances within boundaries of a country or between countries [4,5]. Stable operation of natural gas pipelines is a substantial factor in the socioeconomic development of Iran. Having the second largest natural gas reserves in the world, natural gas is of strategic significance for the country with great potential for export to Europe and eastern neighbors. In the national macro plans, Iran targeted increasing gas extraction, focusing on shared gas fields, to rank the second global natural gas producer. For this purpose, the National Iranian Gas Company (NIGC) must increase its gas transmission potential and develop gas pipelines. NIGC intends to increase the share of natural gas in the country's energy portfolio up to 70 percent $[6,7]$.

Natural gas projects are characterized by massive capital investments [8]. Selecting proper routes and effective project management are essential for avoiding failure and deviation from the strategic plan. Project portfolio selection is a challenging periodic 
activity that requires effective allocation of resources to a subset of possible projects in line with an organization's strategies and objectives without violating indispensable constraints in order to achieve future success and competitiveness of the organization [9].

In order to survive in the competitive environment and ensure sustainability in future, corporations must select an appropriate portfolio of projects [10]. The proposed framework here aims to integrate sustainable strategic alignment with dynamic project interdependency in the project portfolio selection problem.

Projects turn an organization's vision into reality [11]. Ample literature acknowledges that a project portfolio reflects and affects an organization's strategic objectives [12]. Strategy planning is often considered a top management level activity, while project management involves detailed operational plans at micro level. However, this view fails to recognize the mutual relationship between both areas [13]. To establish a link between the NIGC's strategy and project portfolio management, project portfolio selection criteria should be derived from strategic goals [14]. Following the link led to successfully implementing strategies and achieving a portfolio of projects consistent with the strategic objectives.

In a system of components, the overall system's performance depends on not only the individual components but also their interactions [15]. The importance and necessity of acknowledging project interdependencies have repeatedly been emphasized in the literature [16]. Interactions between any pair of project sets can be classified into the complementary and substitute effects. Super-additive value synergy refers to the complementary effect between two projects $(a)$ and $(b)$, which occurs when the value of a joint selection of projects is greater than the sum of their individual selection values: $\operatorname{Value}(a, b)>\operatorname{Value}(a)+\operatorname{Value}(b)$. Sub-additive value synergy, on the other hand, is the substitute effect, when the overall value of a joint selection of projects is less than the sum of their individual selection values: $\operatorname{Value}(a, b)<\operatorname{Value}(a)+\operatorname{Value}(b)$.

The development and execution of a structured decision procedure requires defining the explicit termination criteria. The main causes of terminating a project are lack of customer commitment, political pressure, lack of critical resources, and strategic direction changes [17]. Adjusting ongoing projects allows allocating more resources to other suitable projects.

Project portfolio selection problems are inherently complex due to a wide range of conflicting quantitative and qualitative evaluation criteria and numerous dynamic projects, which may be linked by interdependencies and aligning to strategic planning [18]. The literature on this subject has concluded that a single methodology does not meet all the necessary requirements of project portfolio selection, because each method has its advantages and disadvantages [9]. Most of these methods require value judgments, while the Measuring Attractiveness by a Categorical Based Evaluation Technique (MACBETH) considers the preferences of Decision Makers (DMs) in terms of qualitative pairwise comparison judgments for the difference in values. In this paper, a hybrid approach comprising MACBETH and integer programming is used to solve a sustainable natural gas pipeline project portfolio selection problem.

The rest of the paper is organized as follows. Section 2 reviews the relevant previous studies. Section 3 addresses an integrated framework for project portfolio selection. In Section 4, the model is adopted for selecting a natural gas project portfolio in a real case study. Computational results and sensitivity analysis by applying the model are presented and discussed in Section 5. Finally, Section 6 presents some remarks and recommendations for future research.

\section{Literature Review}

The classic project portfolio selection problem maximizes the value of portfolio while balancing available resources with the selected projects [19]. Among a variety of studies that have been conducted to deal with optimization of portfolios, the integrated framework proposed by Archer and Ghasemzadeh [20] could be a reference. 


\subsection{Sustainable Strategic Project Portfolio Selection}

While strategy formulation has received significant attention in the previous research, strategy implementation remains an underestimated area. The main reason for this gap seems to be that strategy implementation is more case-dependent than strategy formulation. Literature states that project portfolio management bridges the distinction between the formulation and implementation of strategy $[13,21]$. To build a portfolio optimization method, selecting the evaluation criteria that support the organization's strategic energy goals is substantial [22]. Canbaz and Marle [18] employed a project-objective contribution score matrix to show the contribution level of projects to the organization's strategic objectives. Using the contribution degree of projects to the achievement of strategic objectives, GarcíaMelón et al. [23] presented an approach to prioritizing a project portfolio for alignment with the organization's strategic objectives. Wu et al. [24] developed a model for distributed energy generation portfolio selection, which covered alignment along with the strategic objectives, uncertainty, and project interactions, simultaneously. Adopting a strategic portfolio, Debnath et al. [25] concluded that efficient strategic portfolio management leads to resource availability for business and has the impact needed from both the organization and society.

Khalili-Damghani and Tavana [26] proposed a conceptual framework that integrates the sustainability and strategic themes with the portfolio selection procedure. While the sustainable focus on project portfolio evaluation selection may lead to long-term benefits for organizations [27], few practical works consider sustainability issues in the project portfolio selection context [28]. Dobrovolskiene and Tamošiuniene [28] developed a sustainabilityoriented portfolio model by integrating a sustainability index of projects into the classic Markowitz mean-variance framework. They concluded that considering sustainability alters the structure of a portfolio. Various approaches defined sustainability using a combination of three dimensions-namely, the environmental (ecological), economic, and social dimensions $[27,29]$. Some criteria from the technical concerns are suggested to be integrated into the sustainability assessment [30]. Kwast-kotlarek and Hełdak [31] considered four evaluation criteria, including technical costs, economic costs, social costs, and environmental costs for the evaluation of gas pipeline investments.

\subsection{Project Interdependencies within a Portfolio}

One motivating factor behind the need to consider interdependency is that this characteristic exists in real problems. Moreover, the risk of selecting a wrong project without considering the interdependencies is more critical than the challenges of data gathering for modeling [32]. Waste of resource, slippage of schedule, waste of budget, and inter-project competition are some results of ineffective management of project interdependencies [33].

The interdependency issue can be looked upon from different aspects. Thompson defined "interdependency as a contingent relationship among tasks or activities" [34]. Various types of models have been developed to deal with project interdependencies in a portfolio. Santhanam and Kyparisis [35] formulated a nonlinear 0-1 programming problem in which the model's objective function considered synergistic benefit interdependencies and the constraints took resources and technical interdependencies into account.

Schmidt [36] developed a model to evaluate the combined effect of cost, benefit, and outcome interactions. They formulated the objective function using the projects' overall values and the value of their interactions. The resource interaction was presented in quadratic constraints. To represent interactions, Eilat et al. [37] generalized the model presented by Schmidt [36] to the cases with multiple inputs and outputs. They used it to pre-process the data for the subsequent evaluation. Ghapanchi et al. [38] customized interdependencies of the joint account projects in the model proposed by Eilat et al. [37] in terms of input and output as well as project uncertainties using fuzzy variables.

Dickinson et al. [39] proposed a nonlinear, integer program model using a dependency matrix that quantified the benefit interdependencies between projects to optimize Boeing Company's project portfolio selection. Stummer and Heidenberger [40] presented 
a general mathematical model for any given subset of interdependent projects. When a portfolio contained at least a given number of projects in an interdependent subset, the interdependent subset exerted effect on the total benefit of the portfolio. Liesiö et al. [41] used the general constraint presented by Stummer and Heidenberger [40] to consider project interdependencies and extended the robust portfolio modeling (RPM) framework, which modeled incomplete information on project costs and variable budget levels. Canbaz and Marle [18] proposed a formulation in which benefit and outcome interactions were inserted as output factors in the problem and resource interactions were inserted as input factors. Using Bayesian network (BN) methodology, Ghasemi et al. [42] considered project interdependency risks in their model.

To the best of our knowledge, three methods exist for showing interdependency in the literature: tabular list, dependency matrices, and Visual Project Mapping (VPM). In an exploratory study, Killen and Kjaer [43] indicated that the creation of graphical network displays of projects and their interdependencies had the potential to be used as a tool to facilitate project portfolio management and support strategic portfolio decision making.

\subsection{Dynamic Project Portfolio Selection}

Portfolio selection problems can be split into two major categories: dynamic and static [37]. The static portfolio involves situations in which all the considered projects at the decision point are candidates. The dynamic category consists of ongoing projects-denoted as active projects - and a set of candidate projects. The organization deals with put-on-hold or termination of active projects and starting new projects. Termination of projects occurs due to not performing as expected in meeting the portfolio criteria or in favor of another project [44]. Various emotional and political factors prevent projects from stopping at an escalation decision point [45]. Some reasons mentioned for perceived barriers are "sunk cost effect, or escalation of commitment" [46], "we are almost there" argumentation [47], "defense by design" [48], and "protecting manager's "pet" project" [45].

Adjusting existing projects has not drawn the attention it deserves and few research works have been done to solve the dynamic project portfolio selection problem. Huang et al. [49] hybridized cellular automation and particle swarm optimization (PSO) to find an optimal project selection and adjustment of existing projects. Huang et al. [50] developed an optimization model for handling an international project portfolio selection problem that comprised existing project adjustment. Their results showed that more investment return could be obtained when new project selection and adjusting existing projects were simultaneously considered. Li et al. [10] illustrated an uncertain mean-variance mixed-integer nonlinear model focusing on dynamic project portfolio selection with divisibility. They did not take real-life aspects, such as interdependence and resource constraints, into accounts.

This article focuses on assessing the major natural gas transmission pipeline projects crossing Iran. The projects are in the development phase, while according to the feasibility analysis, the characteristics of pipeline routes, the resources required, and future benefits are specified. The proposed project portfolio selection approach aims to convert DMs' preferences into value functions considering multiple sustainable strategic concerns, the possibility of project termination, and the presence of projects interdependencies. Value measurement is tackled through the MACBETH approach using non-numerical pairwise comparisons questioning protocol. Accordingly, the present study's contribution is to put forward a multi-attribute decision model in order to select mid-stream gas projects and allocate resources to an appropriate portfolio aligned with the organization's strategy. For this purpose, the proposed model takes three key issues into account, namely the integration of strategic criteria, put-on-hold or termination of active projects, and projects' interdependencies in the portfolio selection process. According to our literature review, no studies have developed any similar approach in the portfolio selection context; none of them has considered the three aspects described above at the same time either, whereas all of them are critical for selecting an appropriate portfolio. 


\section{An Integrated Framework for Project Portfolio Selection}

The aim of portfolio selection is to select a subset of projects among candidate projects considering multiple criteria, subject to various constraints. Formally, let $X=$ $\left[x_{1}, x_{2}, \ldots, x_{n}\right]$ denote a set of $n$ candidate projects that are evaluated with regards to $K$ criteria. The value of project $x_{i}$ on the $k$ th criterion is $V_{i}^{k}$. The overall value of project $x_{i}$ represents the weighted average of its values, which is shown as Equation (1).

$$
V_{i}=\sum_{k=1}^{K} w^{k} V_{i}^{k}
$$

Subject to $\sum_{k=1}^{K} w^{k}=1$ and $w^{k} \geq 0$. where $w^{k}$ is the relative weights of $k$ th criterion. For the portfolio $p r=\left[x_{1}, x_{2}, \ldots, x_{n}\right], x_{i}$ is a binary variable implying that the $i$ th project belongs to the portfolio at value one and does not belong to it at value of zero. The basic formulation of the overall value of portfolio $p r$ is given by Equation (2):

$$
V(p r)=\sum_{i=1}^{n} \sum_{k=1}^{K} w^{k} V_{i}^{k} x_{i}
$$

The proposed framework is a dynamic project portfolio selection that considers project interdependencies and supports the organization's strategic goals. It assumes a situation where a set of $n$ project proposals are given. Moreover, it is supposed that the projects' data are precise. The DMs' experience and knowledge are indispensable to acquiring viable results from any decision-making process. Therefore, finding the right panel of experts is essential to facilitate this process [23]. Another issue that could help an organization with achieving its goals is selecting an integral set of criteria. In this research, the evaluation criteria are considered independent.

The proposed framework has three main modules. The first module is concerned with the integration of sustainable strategic criteria in the project portfolio selection process. The first module's output is a set of areas of concern supporting the organization's strategic objectives. In the second module, a portfolio project selection procedure that considers on-going projects is proposed. The second module is assumed to deliver a set of projects that consider potential projects and take ongoing projects with overall negative values into account. The output of this module is providing opportunities for organizations to allocate limited resources to other suitable projects. One step further, in the third module, the projects' interdependencies are embedded in the portfolio selection process. In addition, to assess the projects' importance to reaching the organization strategies, the influence of certain projects on the other selected projects of the portfolio is evaluated. Considering sustainable strategic concerns, ongoing projects, and project interdependencies ensure that limited resources are properly allocated to the projects' portfolio aligned with the organization's strategy. The details of the proposed framework depicted in Figure 1 are as follows: 


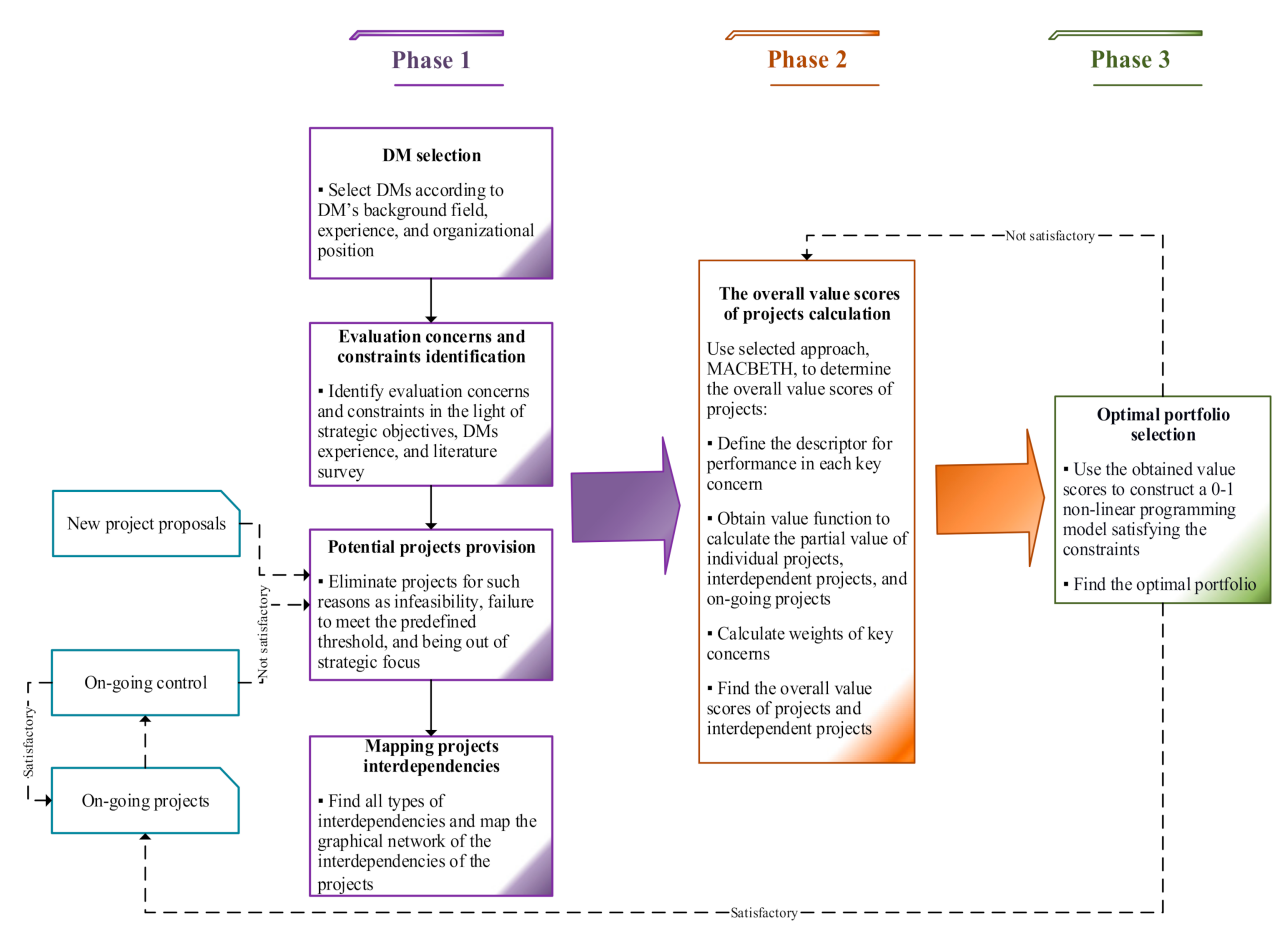

Figure 1. Framework for dynamic portfolio selection considering sustainable strategic alignment and project interdependencies through value analysis.

\subsection{Preliminary Stage Phase}

The preliminary stage is composed of the following four steps:

\subsubsection{Identifying the DMs}

The selection of experts with relevant experience and knowledge is a crucial factor in success. DMs' participation is a requisite aid for researchers to implement the evaluation framework [51]. Therefore, finding the right experts who have a systemic view and proper awareness of different aspects of the company is essential [23]. Based on the background field, working experience, and organizational position, DMs involved in the projects are invited for decision making.

\subsubsection{Identifying Evaluation Concerns and Constraints}

Since any set of evaluation factors is problem-specific, there is no universal methodology to determine a set of evaluation factors [4]. At this step, for configuring a framework, DMs identify meaningful areas of concern and constraints in light of the strategic objectives, relevant literature, and their experience to appraise the values of projects. Assuming that strategies exist for the organization, guidelines derived from the organization strategy are followed to ensure that the areas of concern recognized by the DMs are aligned with the organization's strategic orientation. In case the organization does not have any stated strategy, the balanced scorecard (BSC) approach could be used to systematically recognize the areas of concern. The area of concern is a family of key concerns. DMs are asked to identify key concerns and specify the descriptor of performance for them [52], reflecting the goals and mission of an organization [53]. The identified ones must be measurable in the context in which DMs agree to a separate evaluation of the impacts of the options [54]. The notion of concern corresponds to the common definition of "objective" by Keeney in [55]. However, many types of them are not actually stated as objectives. To employ an additive value function for modeling the overall value, each key concern requires representing an independent evaluation axis, i.e., the (partial) value of a project with respect to each one should be independent of the project's performance under others [56]. 


\subsubsection{Providing a List of Potential Projects}

After providing a list of candidate projects, feasibility studies and other qualifications required are examined to eliminate infeasible and unpromising projects that do not meet the minimum/maximum threshold [37]. The screening step involves a less formal assessment of the project [57] to identify those candidate projects that are worthy of further evaluation [40].

A company has an existing portfolio with several ongoing projects. In case the performance of the project is attenuated or the projects are no longer affordable, the company needs to adjust some of the existing projects to allocate more capital and resources to other suitable projects.

\subsubsection{Preparing the Map of Project Interdependencies}

To find all the meaningful types of interdependencies, either Delphi or Brainstorming method is employed. Killen and Kjaer recommended Visual Project Mapping (VPM) as a technique to present a graphical network map of the projects and their interactions within a portfolio [43]. In a complex project portfolio, VPM can facilitate finding node topology and connectivity as well as visualizing multi-level dependencies more clearly than a text-based list or a dependency matrix [43]. For all types of dependency, DMs are asked to visualize the interdependencies of projects.

\subsection{Building the Optimization Model Phase}

In this phase, the MACBETH process is applied to find the overall value scores of projects. Performance descriptor for each key concern is used to formulate the performance of each project based on each single key concern. MACBETH questioning procedure is used to calculate the partial scores of projects and combinations of interdependent projects considering all related types of interdependency. The weights of key concerns are calculated based on the MACBETH value judgments and each project's overall value across all the key concerns is estimated.

\subsection{Project Portfolio Selection Phase}

The third phase selects the optimal portfolio of projects. The overall value scores of projects are used to obtain the objective function. Considering project interdependencies, objective function and constraints are formulated. A $0-1$ non-linear programming model is constructed and solved to find the subset of projects satisfying the constraints that maximize the portfolio's overall value.

\section{Modeling of the Iranian Gas Engineering and Development Company (IGEDC) Gas Pipeline Project Portfolio Selection}

The proposed model seeks to develop a portfolio through a value-focused approach, which integrates three pillars of the portfolio, namely, sustainable strategic orientation, projects' interdependencies, and ongoing projects adjustment. The use of values in public sector decision problems has become popular. The main idea behind such approaches is to allow the DM to capture, analyze, and understand all the values involved to structure the value system [58]. Within multi-criteria decision analysis (MCDA) approaches, MACBETH is a value elicitation technique that builds a value measurement scale on each key concern based on qualitative judgments of difference in values. MACBETH is adjusted for the evaluation of the organizational objectives related to prioritizing gas midstream projects within a portfolio of IGEDC. IGEDC has been established to implement gas procurement plans. Pipeline transmission is the most popular form of gas transmission. IGEDC is authorized to deal with economic, technical, and feasibility studies of the gas storage and gas transmission projects. Transmission gas pipeline is a public project and refers to pipelines with 1000 PSI nominal pressure and sizes ranging from 10 to 56 inch. Twentynine cross-country gas pipeline projects in long paths from 8 to $270 \mathrm{~km}$ were studied. The projects were linear and needed to calculate all the impact dimensions along the routes. 
Measures of value, that is, value functions, transformed the performance of gas pipeline projects with each impact dimension into value scores for IGEDC.

Quantifying interdependencies of projects and adjustment of ongoing projects make incorporating the inexorable features in the evaluation of a portfolio possible. In the following, a discussion about taking the steps of the model presented in Section 3 is presented to give a clear and practical description of implementing the model for a gas company.

\subsection{Preliminary Stage Phase}

\subsubsection{Identifying the DMs}

DMs have an essential role in project portfolio selection. Five experts with diverse disciplines, who worked at various departments of the company, were selected to collaborate on implementing the project portfolio selection process. The selected experts were invited and given the characteristics of the problem and the proposed framework. Then, they were asked to participate in the project portfolio selection procedure. Detailed information about the experts is presented in Table 1.

Table 1. Information on the experts.

\begin{tabular}{lcc}
\hline DMs & Expertise & Work Experience (Years) \\
\hline $\mathrm{DM}_{1}$ & Strategic planning manager & 20 \\
$\mathrm{DM}_{2}$ & Project manager & 15 \\
$\mathrm{DM}_{3}$ & Environmental expert & 12 \\
$\mathrm{DM}_{4}$ & Gas pipeline execution engineer & 10 \\
$\mathrm{DM}_{5}$ & Economic expert & 10 \\
\hline
\end{tabular}

\subsubsection{Identifying Evaluation Concerns and Constraints}

Despite the significant role of the economic criteria, considering the strategic orientation is essential in finding the optimal portfolio [13]. Relevant literature as well as NIGC's strategies are investigated and the Iranian 6th National Plan is reviewed. Then, the results were presented to DMs and they were asked to, according to their experience, derive compatible evaluation factors with the company's strategies and national macro plans. Among the identified concerns, according to [59], DMs selected the set of concerns that address different aspects, including complete, operational, decomposable, non-redundant, and minimal. To identify and select the evaluation concern, one individual interview with each DM and two rounds of interactive decision conferences were held. At the end of the process, DMs declare that there is no missing concern. Also, no conflicting opinions were received from the DMs. DMs obtained the following sustainability strategic evaluation concerns to construct a hierarchical value-model:

\section{- Economic concerns}

Due to the requirement of significant capital investments for the construction of natural gas transportation, considering economic concerns is essential. In some cases, straight pipeline routes appear to be the most economical ones. However, the results of the pipeline construction show that straight pipeline routes or shortest routes are not necessarily the most economical or best route in practical situations [60]. Net Present Value (NPV) is a well-attended method for the appraisal of long-term energy projects [61]. It is used to maximize the investment return of the portfolio. This factor investigates the full route development to capture the project's cash flow, including the initial capital investment, annual operational and maintenance expenses, and annual revenue over its entire life. In case of termination of an ongoing project, salvage value and reputation cost are included in NPV. The details of the calculation of NPV are shown in Equations (A1) and (A2).

\section{- Environmental concerns}

Within project management problem, the environmental dimension has been widely regarded [28]. Gas pipeline projects have environmental impacts on a variety of natural 
ecosystems. Differences in environmental effects of projects' construction depend on the characteristics of the ecosystems of the project's surrounding environment. Much damage occurs in the installation stage due to the removal of topsoil and vegetation [62]. Destruction of the soil structure and disturbance of vegetation occur along both sides of pipelines and might affect wildlife habitat. Damage of surface vegetation aggravated soil erosion [63]. The pipelines sometimes traverse rivers or sea and change ecological function and marine life [64].

Quantitative environmental impacts should be considered as an integral part of the project management process to accomplish environmental sustainability [65]. For the pipeline projects to pass through any protected area or cultural heritage, one needs the approval of the responsible authority.

To assess environmental impacts of the natural gas pipeline construction, the proposed model should incorporate the following key concerns:

- Avoiding/minimizing pipeline construction within or near the protected area.

- $\quad$ Avoiding/minimizing intersection with rivers, seas, and surface water.

- Minimizing land use changes and vegetation cover removal.

- Social concerns

Deployment of urban infrastructures improves the quality of the living environment of urban residents, contributes to economic growth, and ensures a sustainable supply of energy [66]. Natural gas is considered not only an economic infrastructure sector but also has a substantial social impact. Considering social aspects is critical to evaluate natural gas projects [67]. Social impacts refer to the effects produced by the construction of pipeline projects on communities.

To assess the social factors associated with the natural gas pipeline implementation, the model considers the following key concerns:

- Avoiding/minimizing routes that have not kept their standard distances from populated areas.

- Maximizing the number of households of developed regions with access to natural gas.

- Maximizing the number of households living in less developed regions of the country with access to natural gas.

- Maximizing the number of households living in cold areas with natural gas access.

- Technical concerns

The technical concerns refer to those associated with the constructability of gas pipeline routes. Based on the feasibility study, route barriers, technical issues, and construction requisites are considered for each project. To evaluate the technical factors of the natural gas pipeline construction, the model considers the following key concerns:

- Avoiding/minimizing the routes that cross areas with steep slopes, and other unfavorable land features.

- Avoiding/minimizing the routes that intersect with existing pipelines, highways, high-voltage power lines, and other existing infrastructure.

Figure 2 depicts the hierarchical structure of the portfolio selection model in the value tree format. There are four areas of concern at the first level, i.e., economic, environmental, social, and technical, as defined by corporate strategic planning. The key concerns were determined by the DMs and represented at the second level. For example, three key environmental concerns were identified: Effect on the protected area, effects on surface water resources, and effect on the vegetation cover. The performance descriptor for each key concern is presented in Table 2. All key concerns are considered positive; in the case of qualitative descriptors, a low-risk descriptor or a high-benefit descriptor indicates high performance. When the performances of two hypothetical pipeline projects $\mathrm{X}$ and $\mathrm{Y}$ are equivalent in terms of all evaluation criteria, the DMs could not find any key new concern to differentiate $X$ from $Y$. In structuring the criteria, overlaps between evaluation concerns were eliminated. 


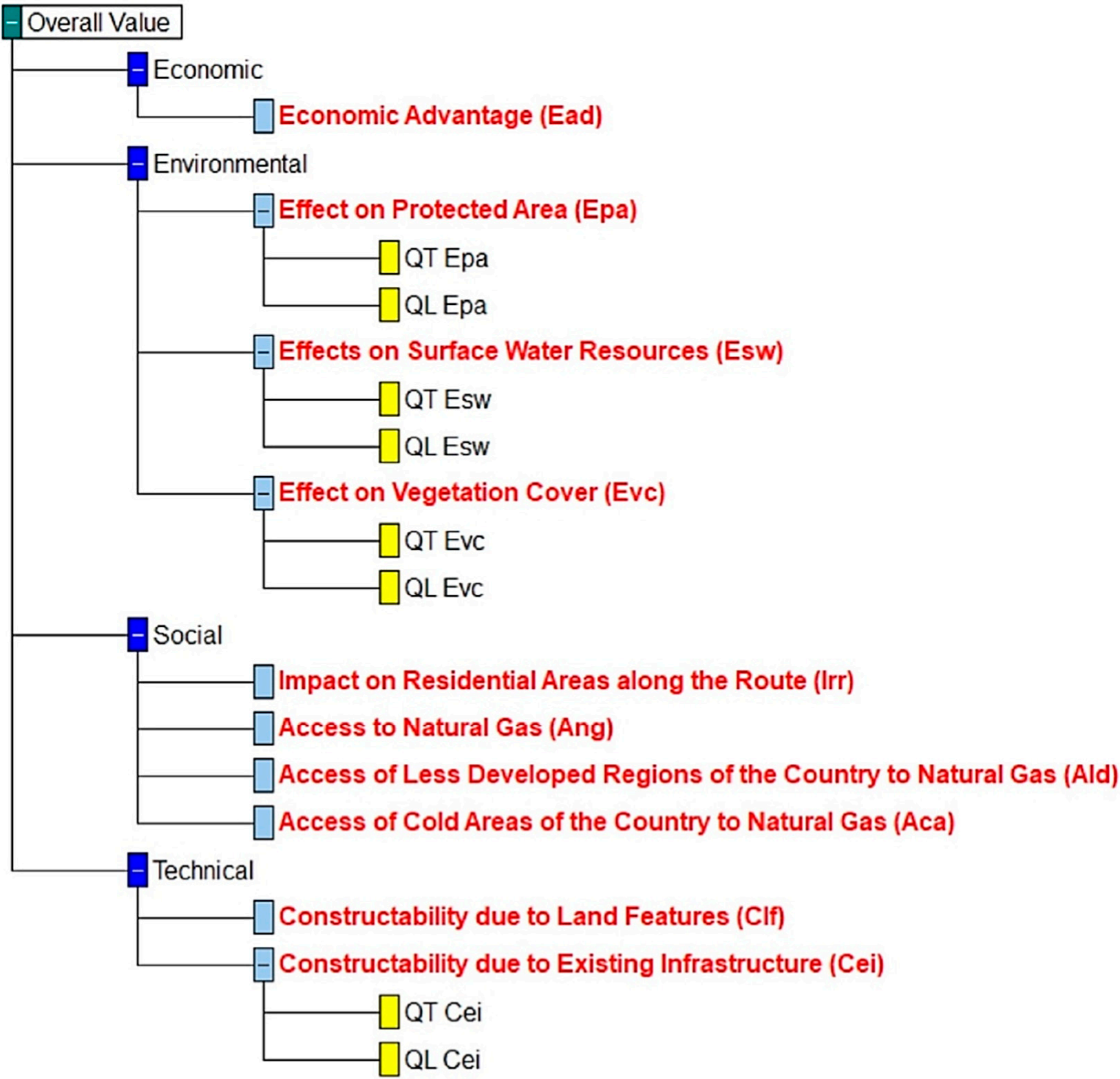

Figure 2. MACBETH value tree for evaluation of gas pipeline projects.

Table 2. Areas of concern and types of performance descriptor.

\begin{tabular}{cllll}
\hline Areas of Concern & \multicolumn{1}{c}{ Key Concerns } & Abbreviation & $\begin{array}{c}\text { Type of } \\
\text { Descriptor }\end{array}$ & Descriptor of Performance \\
\hline \multirow{2}{*}{ Economic } & Economic advantage & Ead & $\begin{array}{l}\text { Quantitative } \\
\text { The project's net present value (The } \\
\text { details of the calculation of NPV are } \\
\text { shown in Appendix A) }\end{array}$ \\
\hline & Effect on protected area & Epa & $\begin{array}{l}\text { Quantitative/ } \\
\text { Qualitative }\end{array}$ & $\begin{array}{l}\text { Equivalent areas of the reference } \\
\text { protected area of the project located } \\
\text { in protected areas }\end{array}$ \\
\cline { 2 - 5 } & $\begin{array}{l}\text { Effect on surface } \\
\text { water resources }\end{array}$ & Esw & $\begin{array}{l}\text { Quantitative/ } \\
\text { Qualitative }\end{array}$ & $\begin{array}{l}\text { Equivalent number of intersections } \\
\text { with reference surface water bodies }\end{array}$ \\
\cline { 2 - 5 } & $\begin{array}{l}\text { Effect on } \\
\text { vegetation cover }\end{array}$ & Evc & $\begin{array}{l}\text { Quantitative/ } \\
\text { Qualitative }\end{array}$ & $\begin{array}{l}\text { Equivalent areas of the reference } \\
\text { vegetation cover removed }\end{array}$ \\
\hline
\end{tabular}


Table 2. Cont.

\begin{tabular}{|c|c|c|c|c|}
\hline Areas of Concern & Key Concerns & Abbreviation & $\begin{array}{c}\text { Type of } \\
\text { Descriptor }\end{array}$ & Descriptor of Performance \\
\hline \multirow{4}{*}{ Social } & $\begin{array}{l}\text { Impact on residential } \\
\text { areas along the route }\end{array}$ & Irr & Quantitative & $\begin{array}{l}\text { Number of households affected due } \\
\text { to short distance from the } \\
\text { pipeline route }\end{array}$ \\
\hline & Access to natural gas & Ang & Quantitative & $\begin{array}{l}\text { Number of households of developed } \\
\text { regions which will access to } \\
\text { natural gas }\end{array}$ \\
\hline & $\begin{array}{l}\text { Access of less developed } \\
\text { regions of the country to } \\
\text { natural gas }\end{array}$ & Ald & Quantitative & $\begin{array}{l}\text { Number of households living in less } \\
\text { developed regions of the country } \\
\text { which access to natural gas }\end{array}$ \\
\hline & $\begin{array}{l}\text { Access of cold areas of } \\
\text { the country to natural gas }\end{array}$ & Aca & Quantitative & $\begin{array}{l}\text { Number of households living in cold } \\
\text { areas which access to natural gas }\end{array}$ \\
\hline \multirow[b]{2}{*}{ Technical } & $\begin{array}{l}\text { Constructability due to } \\
\text { land features }\end{array}$ & Clf & Qualitative & Five qualitative performance levels \\
\hline & $\begin{array}{l}\text { Constructability due to } \\
\text { existing infrastructure }\end{array}$ & Cei & $\begin{array}{l}\text { Quantitative/ } \\
\text { Qualitative }\end{array}$ & $\begin{array}{l}\text { Equivalent number of the reference } \\
\text { type intersections with the } \\
\text { pipeline route }\end{array}$ \\
\hline
\end{tabular}

Some key concerns embody a Quantitative Component (QT) and a Qualitative Component (QL) which ensure a comprehensive evaluation. For instance, the related evaluation of affected protected regions should consider their area and quality (QT Epa and QL Epa, respectively, in Figure 2).

Multiple constraints can be incorporated into the gas route selection process; for this assessment, four basic constraints include exclusive projects' constraints, mandatory projects' constraints, technical projects' constraints, and budget constraints, which have been determined.

\subsubsection{Providing a List of Potential Projects}

A list of projects including 27 candidate projects and two active projects was identified so that they could be considered in the project portfolio selection process. It is worth mentioning that projects that had been unfeasible technically or passed through restricted protected areas were removed from the process. Common reasons for adjusting the ongoing pipeline projects include reduced project performance due to breach of contract, increase in project expenditures due to currency fluctuations, difficulties with technical specifications, and new environmental aspects that make the project no longer affordable. Thereby, these reasons can make a project unattractive, reprioritize it, and eventually lead to its termination.

\subsubsection{Preparing the Map of Possible Projects Interdependencies}

In many portfolio decision-making situations, it is desired to take into account not only the characteristics of the individual projects but also the manner in which they interact with each other [68]. The entire system of energy transmission as an integral infrastructure is tightly coupled [69], which means its performance is dependent on not only the individual components but also their interactions.

These interactions are evaluated in a more qualitative way; in addition, they have been tackled using several quantitative models to analyze the relations between projects $[40,70]$. Thus, considering interdependencies is a topic of interest in this context. Particularly, for selecting a gas pipeline project portfolio, DMs detected five types of interdependencies as described below.

DMs identified sub-additive cost synergy and environmental effect interdependency for natural gas projects, which followed a parallel path when two projects coexisted in the same project portfolio. Cost interdependencies would result in a cost decrease for each 
project and take place when a portfolio's total cost is less than the sum of individual costs of the projects [71]. Cost interdependency is mainly due to sharing costs of land acquisition and the environmental interdependency results from sub-additive land-use changes and removal of vegetation cover. These types of synergies are calculated by evaluating the length of the shared path. It is worth mentioning that the sub-additive cost synergy would be conducive to super-additive NPV synergy in this case.

The second situation concerning the interdependency of projects is characterized by when two projects coexist in a selected portfolio supply of gas for shared destinations. Implementing these projects with shared customers leads to a substitute effect on the key concerns of social gas supply, sub-additive income synergy, and NPV synergy.

Another type of interdependency identified is technical interdependency. Technical interdependencies emerge when a project belonging to a set of mutually exclusive projects can only be selected if no other project from the set is selected, and if a given project $X$ is contingent upon a set of projects, the project $X$ can only be selected if all the projects in the set are selected. The pipeline projects with the same mission and those projects that constitute a program are technically interdependent. When several projects have the same mission, they are mutually exclusive and at most, one of them must be selected. Also, when a program comprises projects $X$ and $Y$, and the starting point of $X$ is the ending point of $Y$, the selection of $X$ is contingent upon that of $Y$.

Two dimensions are considered in visualizing the project portfolio:

- Actors/component dimension: identifying all the participating actors (projects) in the networks.

- Relationship dimension: The projects can be linked through different types of interdependencies. This dimension focuses on determining types of interdependencies, e.g., cost, NPV, social effect, environmental effect, technical interdependency.

According to the identified interdependencies, a graphical network map of the interdependencies of projects is depicted in the format of Figure 3.

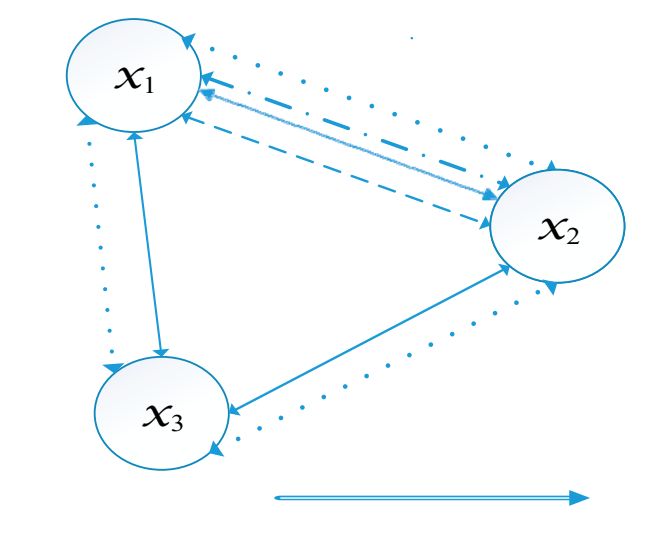

Legend

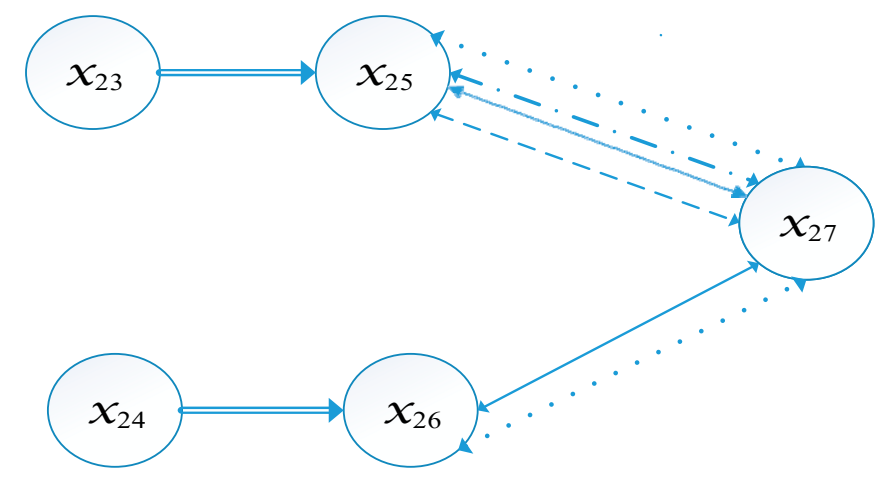

Technical interdependency NPV interdependency Environmental interdependency Social interdependency Cost interdependency

Figure 3. Graphical network map of two identified groups of project interdependencies.

\subsection{Building the Optimization Model Phase}

The literature offers several methods for building multi-criteria value measurement models. Among the proposed methods, MACBETH requires only pairwise qualitative judgments on the difference in attractiveness of the elements of a finite set $X$ and transforms the obtained judgments to interval value scales. MACBETH is an interactive multi-criteria decision-aid approach to value measurement and its original idea was presented in the 1990s by Bana e Costa and Vansnick [72]. If two elements are not equally attractive, to ease 
pairwise comparison, six semantic categories of the difference in attractiveness are applied, namely "very weak", "weak", "moderate", "strong", "very strong", or "extreme". A variety of scientific research pieces in the literature have validated MACBETH by applying it to different evaluation contexts such as human resource management [73], maintenance policies [74], health care [75], energy and environment [52], portfolio selection [76], strategy selection [77], faculty evaluation [78], and logistics [79]. M-MACBETH software provides a graphical tool to support the MACBETH procedure [72].

According to the descriptor of performance, the performance levels of each key concern are defined. DMs are required to rank the mentioned levels in descending order of attractiveness and to select the desired MACBETH semantic category(ies) of difference in the attractiveness levels for each key concern. Based on pairwise comparisons of the differences in the attractiveness of performance levels, M-MACBETH provides a value curve for each key concern, with 0 and 1 assigned to the lower and upper reference levels, respectively.

Value curve converts project performance into a value for the portfolio. In this regard, $P^{k}$ is the performance descriptor of the key concern $k . P_{i}^{k}$ is the performance of gas pipeline $i$ on the key concern $k$. The obtained value function $V^{k}$ is utilized to convert the performance of each gas pipeline $i$ on the key concern $k$ to the partial value score $V_{i}^{k}=V^{k}\left(P_{i}^{k}\right)$.

If the key concerns embody quantitative and qualitative components, then both quantitative and qualitative descriptors of performance can be integrated to assess the performance of gas pipeline projects with respect to the mentioned concerns.

In quantitative/qualitative key concern $k, P_{i}^{k}$ is given by:

$$
P_{i}^{k}=\sum_{q=1}^{Q} Q T_{i q}^{k} f\left(Q L_{q}^{k}\right)
$$

where $q$ is the key concern type $(q=1, \ldots, Q) ; Q T_{i q}^{k}$ is the number/area of intersection/interference of project $i$ in key concern $k$ with type $q ; f\left(Q L_{q}^{k}\right)$ is the number/area of equivalent units for the type $q$ of key concern $k$ based on its quality. The multiplicative relationship between quantity and quality defined in Equation (3) clarifies that the added value of reducing one more $\mathrm{km}^{2}$ of interference in a protected area is not independent of its type/quality.

The definition of $f\left(Q L_{q}^{k}\right)$ in Equation (3) requires trade-off judgments of DMs to convert one unit of each type of key concern into units of a chosen reference type. In the case of protected areas, the Department of Environment of Iran differentiated six types of protected areas. DMs ranked them in descending order in terms of their relative attractiveness as follows: National Nature Reserve (NNR), National Natural Park (NNP), Wildlife Refuge (WR), Conservation Area (CA), Hunting Prohibited Area (HPA), and Reserved Forest (RF).

Then, DMs employed MACBETH to pairwise compare different protected area types in terms of their difference in attractiveness. These pairwise comparisons (including "noninterference" in protected areas) generate a consistent set of qualitative judgments given in Figure 4; for example, the judgment "extreme" in the highlighted cell in the matrix implies that the DMs have judged the reduction of one $\mathrm{km}^{2}$ interference in the National Nature Reserve to be extremely more attractive than that in the Reserved Forest. The conservation area is optionally chosen as a reference to the protected area to which a score of 1 is assigned. DMs adjusted the derived score scales in Figure 4 until they could reach the final agreement on the scoring scale shown in Table 3. According to DMs' opinions, International Lagoon was added to the list of the protected area and its value was considered equivalent to that of National Natural Park. To determine the value function, qualitative judgments on the decreased value of occupying an extra area $\left(\mathrm{km}^{2}\right)$ of the reference protected areas were made. The differences in the attractiveness of the performance levels of the consecutive areas in the protected occupation reference area were identified and compared to fill the matrix of judgments and create a value scale. 
Type of Protected Area

\begin{tabular}{l|c|c|c|c|c|c|c||c|}
\hline 凅 & NNR & NNP & WR & CA & HPA & RF & NI & extreme \\
\hline NNR & no & extreme & extreme & extreme & extreme & extreme & extreme & v. strong \\
\hline NNP & & no & v. strong & extreme & extreme & extreme & extreme & moderate \\
\hline WR & & & no & strong & strong & strong & strong & weak \\
\hline CA & & & no & moderate & strong & positive & very weak \\
\hline HPA & & & & no & weak & moderate & no \\
\hline RF
\end{tabular}

Figure 4. MACBETH judgments on different types of the protected area.

Table 3. Equivalent units for different protected area types.

\begin{tabular}{cc}
\hline Type of Protected Area & $f\left(Q L_{\boldsymbol{q}}\right)$ \\
\hline National Nature Reserve & 5 \\
National Natural Park or International Lagoon & 3 \\
Wildlife Refuge & 1.99 \\
Conservation Area & 1 \\
Hunting Prohibited Area & 0.57 \\
Reserved Forest & 0.29 \\
Non-Interference & 0 \\
\hline
\end{tabular}

Figure 5 shows the value function of areas of the reference protected area. This convex value function indicates that DMs are more sensitive to the differences of occupying less protected areas than those of occupying more protected areas. In the horizontal axis, note that non-interference in the reference protected area is considered to represent upper performance, while $0.05 \mathrm{~km}^{2}$ interference in the reference protected area is considered to denote the lower performance of the gas pipeline project. The value function obtained for the key concern was discussed and approved by the DMs involved in the study. MMACBETH automatically verifies the consistency of judgments and in case of inconsistency, some suggestions have been suggested to resolve it.

Based on the obtained value functions of the key concerns, the performance of each gas pipeline project on each key concern could be translated into value scores.

The qualitative swing weighting procedure of MACBETH was used to weigh the key concerns [72]. Based on the upper and lower references of performance of gas pipeline projects in each key concern, ten swings were ranked in terms of their relative attractiveness. "Suppose all key concerns are at their lower performance level for a gas pipeline project; on which key concern would a move from lower to upper performance be most attractive?" The DMs were asked to identify the next most attractive swing until ranking these ten. Next, DMs compared the difference in global attractiveness of each pair of swings using MACBETH categories. M-MACBETH-generated numerical weights are representative of the given pairwise qualitative comparison. Figure 6 presents a pairwise qualitative comparison between the swings of the key concerns and the set of weights validated by DMs. 


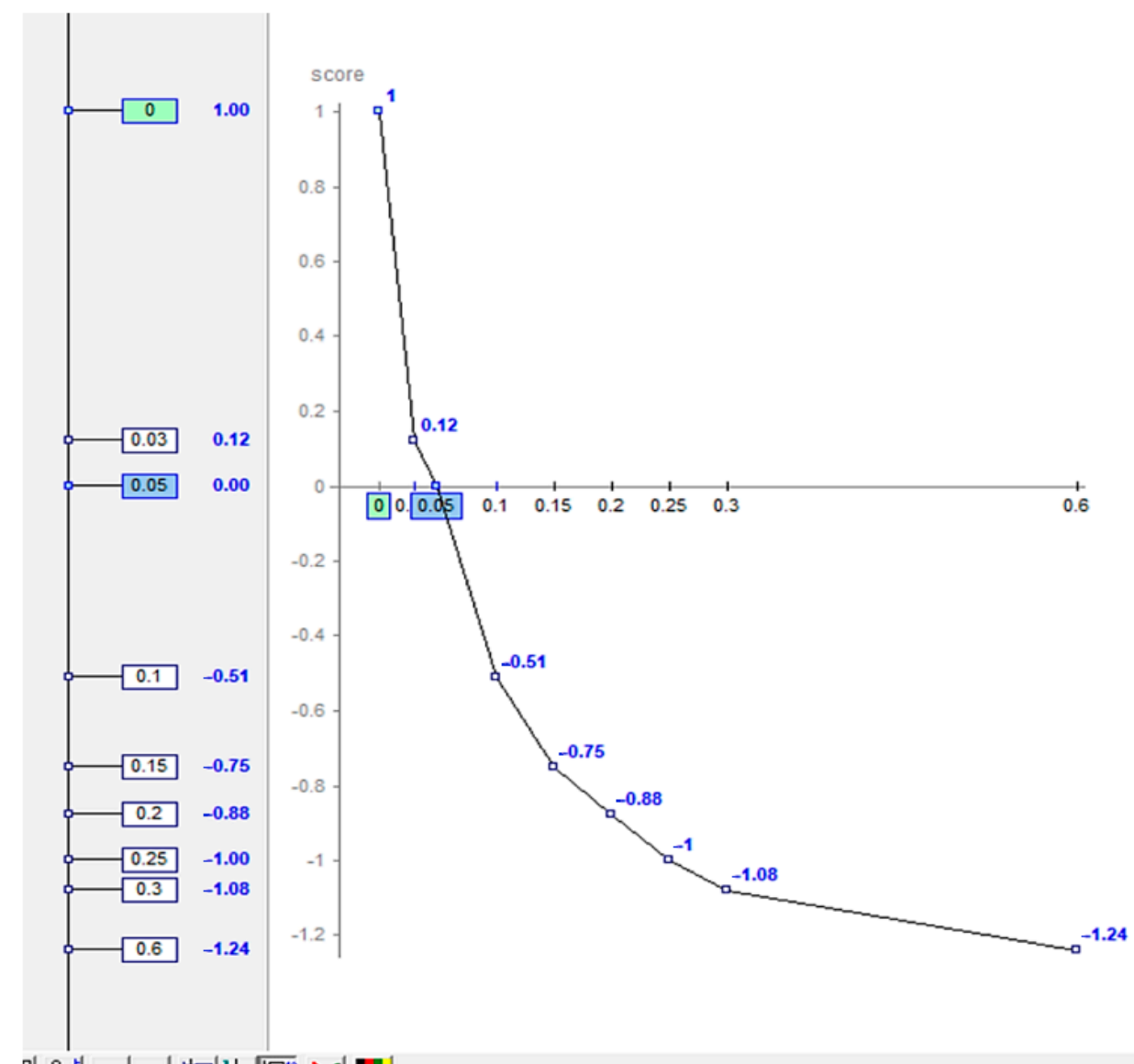

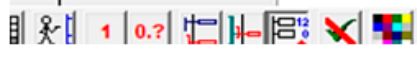

Figure 5. Value function for the equivalent areas of the reference protected area.

Wh. Weighting (Overall Value)

\begin{tabular}{|c|c|c|c|c|c|c|c|c|c|c|c|}
\hline 圆 & [Epa] & [Aca] & [ Ead] & [Ald] & [Ang] & [ $\mathrm{Clf}$ ] & [Esw] & [Evc] & [ I Irr] & [Cei] & [ all lower] \\
\hline [Epa ] & no & vweak-weak & positive & positive & positive & positive & strg-vstr & v. strong & positive & positive & extreme \\
\hline [Aca] & & no & very weak & mod-strg & v. strong & positive & positive & positive & vstrg-extr & positive & extreme \\
\hline [Ead] & & & no & weak & positive & positive & positive & positive & positive & positive & extreme \\
\hline [Ald] & & & & no & strong & positive & positive & positive & $\mathrm{v}$. strong & positive & extreme \\
\hline [Ang] & & & & & no & moderate & positive & positive & strong & positive & vstrg-extr \\
\hline [Clf] & & & & & & no & very weak & positive & positive & strg-vstr & strong \\
\hline [Esw] & & & & & & & no & moderate & positive & positive & mod-strg \\
\hline [Evc] & & & & & & & & no & moderate & positive & mod-strg \\
\hline [Irr] & & & & & & & & & no & strg-vstr & mod-strg \\
\hline [Cei] & & & & & & & & & & no & moderate \\
\hline [ all lower]] & & & & & & & & & & & no \\
\hline
\end{tabular}

Consistent judgements

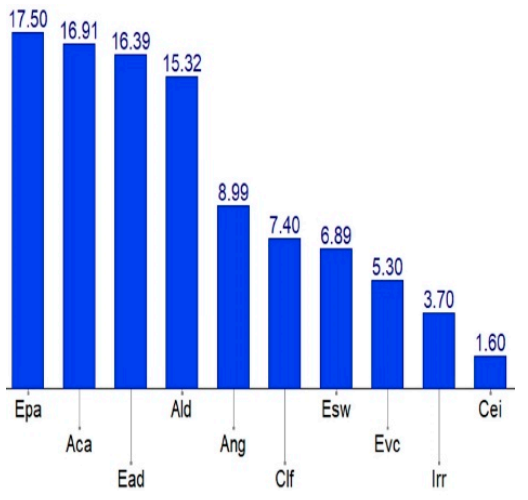

Figure 6. DMs' weighting judgments and respective MACBETH weights.

The additive evaluation model (Equation (1)) is used to determine the overall value $V_{i}$ of the gas pipeline $i$, taking all the key concerns into consideration. $V_{i}$ is the overall value of the gas pipeline $i$ irrespective of its interdependency, i.e., a standalone version, among the projects, and $V_{i . j}$ is the value for the gas pipeline $i$ in case there is interdependency between the gas pipelines $i$ and $j$. In case there is no interdependency between the projects $i$ and $j$ and $V_{i . i}=V_{i}, V_{i . j}$ is equal to $V_{i}$. The results of the overall value scores of projects are given in Table 4. Of note, $V_{i}$ is reported as the overall value score of the candidate/active project $i$ and $V T_{i}$ is the overall value of terminating the active project $i$ that takes reputation cost 
and salvage value into consideration. Moreover, Equation (4) is reported as the added value of the joint selection of two projects $i$ and $j$.

$$
\operatorname{Value}(i, j)=\sum_{k=1}^{K} w^{k}\left(V_{i . j}^{k}-V_{i}^{k}+V_{j . i}^{k}-V_{j}^{k}\right)
$$

Table 4. The overall value scores (OVS) of projects.

\begin{tabular}{cccccccc}
\hline Project & OVS & Project & OVS & Project & OVS & Project & OVS \\
\hline$x_{1}$ & 0.87 & $x_{10}$ & 1.45 & $x_{19}$ & 0.19 & $x_{28}$ & -0.04 \\
$x_{2}$ & 0.7 & $x_{11}$ & 1.31 & $x_{20}$ & 0.34 & $x_{29}$ & -0.03 \\
$x_{3}$ & 0.72 & $x_{12}$ & 1.25 & $x_{21}$ & 0.24 & $1-x_{28}$ & -0.09 \\
$x_{4}$ & -0.16 & $x_{13}$ & 1.48 & $x_{22}$ & 0.46 & $1-x_{29}$ & -0.02 \\
$x_{5}$ & -0.04 & $x_{14}$ & 1.28 & $x_{23}$ & 0.11 & $x_{1} x_{2}$ & 0.46 \\
$x_{6}$ & 0.4 & $x_{15}$ & 0.22 & $x_{24}$ & 0.21 & $x_{1} x_{3}$ & -0.45 \\
$x_{7}$ & 0.68 & $x_{16}$ & 0.2 & $x_{25}$ & 0.83 & $x_{2} x_{3}$ & -0.45 \\
$x_{8}$ & 1.03 & $x_{17}$ & 2.58 & $x_{26}$ & 0.92 & $x_{25} x_{27}$ & 0.34 \\
$x_{9}$ & 1.03 & $x_{18}$ & 2.79 & $x_{27}$ & 0.87 & $x_{26} x_{27}$ & -0.54 \\
\hline
\end{tabular}

$x_{i}$ stands for the candidate/active project $i,\left(1-x_{i}\right)$ stands for the terminated project $i$, and $x_{i} x_{j}$ stands for two interdependent projects $i$ and $j$.

\subsection{Project Portfolio Selection Phase}

The formulated mathematical model seeks to compile a portfolio with the highest value, given some constraints and interdependencies between the projects. The multiattribute value of a portfolio is assessed as a sum of the overall scores of the projects selected in the portfolio. The higher the derived score, the better the project. This value model aims to select a portfolio of projects with the highest value in terms of constraints. The value concept is used in the context of the mid-stream gas industry, and MACBETH as an appropriate multi-criteria methodology is used to prioritize gas pipeline projects within a portfolio.

If $p r=\left[x_{1}, x_{2}, \ldots, x_{n}\right]$ is considered a vector representing a portfolio, $x_{i}$ is the binary variable that takes a value of either one or zero, implying that the $i$ th project belongs to the portfolio at value one and does not belong to it at value of zero. The present study aims to choose a subset of $p r$ with the highest value.

As mentioned above, the overall value for a portfolio is considered as the sum of MACBETH-generated values of the projects in the portfolio, taking the interdependency between them and project termination into account.

Considering Equations (2) and (4), we obtain Equation (5), which assigns a value to a portfolio.

$$
V(p r)=\sum_{i=1}^{n} \sum_{k=1}^{K} w^{k} V_{i}^{k} x_{i}+\sum_{i=1}^{n} \sum_{j=1}^{n} \sum_{k=1}^{K} w^{k}\left(V_{i . j}^{k}-V_{i}^{k}\right) x_{i} x_{j}+\sum_{i \in P_{a}} \sum_{k=1}^{K} w^{k}\left(V T_{i}^{k}\right)\left(1-x_{i}\right)
$$

The first term calculates the individual selection values of active/candidate projects. The value of selected projects is added to the value of the portfolio. The second term calculates the added value of a joint selection of interdependent projects. Owing to the interdependency of the projects, they are subject to varying performances in each key concern depending on projects that exist in the selected portfolio. This condition affects the calculation of the value of any given project. In other words, the value of a project depends on a set of projects in a portfolio. Furthermore, adjusting the existing projects affects the value of the portfolio. When a project that belongs to the set of active projects is no longer affordable, the decision is to terminate it. To this end, the value of terminating active projects is considered in the last term.

This study seeks a set of projects that can maximize the portfolio value. Moreover, the proposed model comprises specific conditions such as technical interdependencies, mandated projects, exclusive projects, and budget constraints, all of which should be 
considered in the project portfolio selection. The constraints can either encompass all the projects or those belonging to some clusters. The optimization model is as follows:

$$
\max V(p r)=\sum_{i=1}^{n} \sum_{k=1}^{K} w^{k} V_{i}^{k} x_{i}+\sum_{i=1}^{n} \sum_{j=1}^{n} \sum_{k=1}^{K} w^{k}\left(V_{i . j}^{k}-V_{i}^{k}\right) x_{i} x_{j}+\sum_{i \in P_{a}} \sum_{k=1}^{K} w^{k}\left(V T_{i}^{k}\right)\left(1-x_{i}\right)
$$

s.t.

$$
\begin{gathered}
\sum_{i=1}^{n} I C_{i} x_{i}+\sum_{i=1}^{n} \sum_{j=1}^{n}\left(I C_{i . j}-I C_{i}\right) x_{i} x_{j} \leq B+\sum_{i \in P_{a}} S V_{i}\left(1-x_{i}\right) \\
\sum_{i \in P_{c}} I C_{i} x_{i}+\sum_{i \in P_{c}} \sum_{j=1}^{n}\left(I C_{i . j}-I C_{i}\right) x_{i} x_{j} \geq r_{c}\left(B+\sum_{i \in P_{a}} S V_{i}\left(1-x_{i}\right)\right) \\
\sum_{i \in P_{l}} I C_{i} x_{i}+\sum_{i \in P_{l}} \sum_{j=1}^{n}\left(I C_{i . j}-I C_{i}\right) x_{i} x_{j} \geq r_{l}\left(B+\sum_{i \in P_{a}} S V_{i}\left(1-x_{i}\right)\right) \\
\sum_{i \in P_{m}} x_{i} \geq 1 \\
\sum_{i \in P_{e}} x_{i} \leq R \\
x_{i} \leq x_{j}, \quad(i, j) \in P_{h} \\
x_{i} \in\{0,1\}
\end{gathered}
$$

where $x_{i}=1$ if the project $i$ is selected for the portfolio, and 0 otherwise (Equation (13)). Constraint (7) sets the boundary budget $(B)$ for selecting the projects. $I C_{i}$ is the investment capital needed to implement project $i$ (stand-alone) and $I C_{i . j}$ is the investment capital needed to implement project $i$ when projects $i$ and $j$ coexist in the selected portfolio. This term reflects the interdependencies of the resource constraints. Abandoning the ongoing project $i$ frees $\sum_{i \in P_{a}} S V_{i}\left(1-x_{i}\right)$ capital resources so that more new projects can be selected. In this regard, $P_{a}$ is a set of active projects and $S V_{i}$ is the salvage value of the active project $i$. Balancing constraints (8) and (9) provides funding for projects related to cold and less developed areas respectively, where $P_{c}$ and $P_{l}$ are sets of projects that supply gas to the cold and less developed areas, and $r_{c}$ and $r_{l}$ are minimum percentages of the budget allocated to those projects. Constraints (10-12) formulate management and technical interdependencies between the projects. Due to internal or external restrictions, Equation (10) ensures that at least one of the mandated projects belonging to the set of mandated projects $\left(P_{m}\right)$ must be selected in the portfolio. In Equation (11), the set $P_{e}$ of the exclusive projects implies that at most $R$ projects belonging to this set should be selected in the portfolio. $P_{h}$ denotes the precedence relation set; in other words, if the project $i$ takes precedence over the project $j,(i, j) \in P_{h}$. Finally, Equation (12) formulates technical interdependency of the projects through the precedence relations.

In order to linearize the model, the non-linear relation $x_{i} x_{j}$ should be replaced with the variable $x_{i . j}$ and a set of two linear equations [80]:

$$
\begin{gathered}
2 x_{i . j}-\left(x_{i}+x_{j}\right) \leq 0 ; \\
x_{i}+x_{j} \leq 1+x_{i . j} ;
\end{gathered}
$$

The computational results and sensitivity analysis of applying the proposed model are presented in the following section.

\section{Computational Results}

According to the findings, the highest portfolio value based on the overall values was obtained by the MACBETH method. The model was implemented in GAMS software and the CPLEX solver was used. Computations were conducted using a laptop computer 
featuring an Intel(R) Core ${ }^{\mathrm{TM}}$ i7- 7500U Processor (RAM 12 G) operating within a few seconds of computer time.

The results of the model along with interdependency and termination considerations are shown in Table 5a. Accordingly, 11 candidate projects were included in the portfolio, among which $x_{5}$ was selected as a mandatory project. Two active projects were taken into account in the selection process which, according to the selected portfolio, led to the termination of $x_{29}$ and allocation of more budget to other suitable projects. It was found that this project had new environmental aspects which made it no longer affordable. Despite the decline in NPV, another ongoing project $\left(x_{28}\right)$ was included in the selected portfolio. In this regard, $x_{1}$ and $x_{2}$ are two interdependent projects included in the portfolio. In another approach, the calculation was performed again considering the interdependency and, yet, ignoring the possibility of project termination (Table $5 \mathrm{~b}$ ). Although the ongoing project $x_{29}$ can enter the portfolio, $x_{16}$ and $x_{18}$ are replaced by $x_{15}$ and $x_{17}$ in the portfolio due to budget constraints. To analyze the effects of project interdependencies in the third stage of model implementation, calculations were performed considering the possibility of project termination and ignoring interdependency (Table $5 c$ ). Interdependencies between the pair $\left(x_{1}, x_{2}\right)$ and pair $\left(x_{1}, x_{3}\right)$ were critical factors, and the failure to consider them would lead to removal of $x_{2}$ and inclusion of $x_{3}$ in the selected portfolio. Finally, after analyzing the difference between these three implementations, the DMs opted for the portfolio described in Table 5a.

Table 5. Results of portfolio selection.

a. Projects selected for the portfolio with interdependency and termination considerations

\begin{tabular}{llllllcl}
\hline$x_{1}$ & 1 & $x_{10}$ & 1 & $x_{19}$ & 0 & $x_{28}$ & 1 \\
$x_{2}$ & 1 & $x_{11}$ & 0 & $x_{20}$ & 0 & $x_{29}$ & 0 \\
$x_{3}$ & 0 & $x_{12}$ & 0 & $x_{21}$ & 0 & $1-x_{28}$ & 0 \\
$x_{4}$ & 0 & $x_{13}$ & 1 & $x_{22}$ & 1 & $1-x_{29}$ & 1 \\
$x_{5}$ & 1 & $x_{14}$ & 0 & $x_{23}$ & 0 & $x_{1.2}$ & 1 \\
$x_{6}$ & 0 & $x_{15}$ & 0 & $x_{24}$ & 1 & $x_{1.3}$ & 0 \\
$x_{7}$ & 1 & $x_{16}$ & 1 & $x_{25}$ & 0 & $x_{2.3}$ & 0 \\
$x_{8}$ & 0 & $x_{17}$ & 0 & $x_{26}$ & 0 & $x_{25.27}$ & 0 \\
$x_{9}$ & 1 & $x_{18}$ & 1 & $x_{27}$ & 0 & $x_{26.27}$ & 0 \\
\hline
\end{tabular}

b. Projects selected for the portfolio with interdependency considerations

\begin{tabular}{llllllll}
\hline$x_{1}$ & 1 & $x_{10}$ & 1 & $x_{19}$ & 0 & $x_{28}$ & 1 \\
$x_{2}$ & 1 & $x_{11}$ & 0 & $x_{20}$ & 0 & $x_{29}$ & 1 \\
$x_{3}$ & 0 & $x_{12}$ & 0 & $x_{21}$ & 0 & $x_{1.2}$ & 1 \\
$x_{4}$ & 0 & $x_{13}$ & 1 & $x_{22}$ & 1 & $x_{1.3}$ & 0 \\
$x_{5}$ & 1 & $x_{14}$ & 0 & $x_{23}$ & 0 & $x_{2.3}$ & 0 \\
$x_{6}$ & 0 & $x_{15}$ & 1 & $x_{24}$ & 1 & $x_{25.2}$ & 0 \\
$x_{7}$ & 1 & $x_{16}$ & 0 & $x_{25}$ & 0 & $x_{26.27}$ & 0 \\
$x_{8}$ & 0 & $x_{17}$ & 1 & $x_{26}$ & 0 & & \\
$x_{9}$ & 1 & $x_{18}$ & 0 & $x_{27}$ & 0 & & \\
\hline
\end{tabular}

c. Projects selected for the portfolio with termination considerations

\begin{tabular}{llllllll}
\hline$x_{1}$ & 1 & $x_{10}$ & 1 & $x_{19}$ & 0 & $x_{28}$ & 1 \\
$x_{2}$ & 0 & $x_{11}$ & 0 & $x_{20}$ & 0 & $x_{29}$ & 0 \\
$x_{3}$ & 1 & $x_{12}$ & 0 & $x_{21}$ & 0 & $1-x_{28}$ & 0 \\
$x_{4}$ & 0 & $x_{13}$ & 1 & $x_{22}$ & 1 & $1-x_{29}$ & 1 \\
$x_{5}$ & 1 & $x_{14}$ & 0 & $x_{23}$ & 0 & \\
$x_{6}$ & 0 & $x_{15}$ & 0 & $x_{24}$ & 1 & \\
$x_{7}$ & 1 & $x_{16}$ & 1 & $x_{25}$ & 0 & \\
$x_{8}$ & 0 & $x_{17}$ & 0 & $x_{26}$ & 0 & \\
$x_{9}$ & 1 & $x_{18}$ & 1 & $x_{27}$ & 0 & \\
\hline
\end{tabular}

1 if the project is selected and 0 if not. 


\section{Sensitivity Analysis}

In quantitative models, sensitivity analysis is a widely used method for evaluating the region of validity and stability of the proposed framework results. In this section, this analysis is carried out in two directions including weight and budget variations.

A number of sensitivity analyses were carried out to assess the impact of variation in the relative weights of the key concerns on the obtained results. As observed in Equation (16), the relative weights of several key concerns increased and the rest decreased.

$$
w_{\text {new }}^{k}=w_{\text {old }}^{k}+\alpha w_{\text {old }}^{k}
$$

where $\alpha$ is the percentage of change in the original weight of the key concern $k$. The weights of the rest of key concerns are automatically adjusted so that the sum of new weights is kept in unity, i.e., $\sum_{k=1}^{K} w_{\text {new }}^{k}=1$.

In this work, the weights of the key concerns were measured according to experts' opinions. In addition, different changes in the weights of the key concerns were considered in evaluating the robustness and reliability of the selected portfolio. To this end, eight scenarios were created by altering the weights of ten key concerns shown in Figure 7. Scenarios 1-4 were fabricated according to a 5\% increase in weights of all key concerns belonging to the environmental, economic, social, and technical concerns, respectively. The results shown in Figure 8 indicate that small changes make no difference in the selected portfolio. Scenarios 5-8 were created considering an increase of about 50 percent in weights of key concerns belonging to environmental, economic, social, and technical concerns, respectively.

In Scenario 5, due to a severe increase in the weights of environmental concerns, project $x_{28}$ is no longer affordable. A drastic increase in the weight of the economic concern would lead to removing $x_{24}$ with low performance in NPV, while the high reputation cost of $x_{29}$ would keep it as an active project. A drastic increase in the weights of the two remaining areas of concerns would lead to incorporation of the projects with better performance in the related concerns to the portfolio.

To adjust the sensitivity of the model to budget, the budget variations analysis is performed. Since the company can obtain additional funding from different sources or may encounter some funding restrictions, an analysis has been conducted to evaluate the effects of budget on the portfolio. Hence, four scenarios with low and high variations were considered for two budget conditions: rise-up and decline. The results are presented in Figure 9. Given that gas pipeline projects require high investment, small budget changes do not affect the final selected portfolio of projects. An increase in the budget up to $25 \%$ leads to changes in selected projects.

To fund $x_{26}$ as a project with high investment, $x_{16}$ and $x_{18}$ are replaced by $x_{15}$ and $x_{17}$ in the high rise-up budget scenario. For a scenario with a considerable decline in the budget, $x_{24}$ and $x_{2}$ are removed from the portfolio. In fact, the included projects in the portfolio utilize available budget as much as possible to maximize the value of the portfolio. Likewise, the overall value of the portfolio could be enhanced by funding an extra budget.

According to the results, the portfolio remains consistent unless some extreme variation in the weights of the key concerns or budget appears. Otherwise, sensitivity analysis shows the robustness of the selected portfolio. The conducted sensitivity analysis would help the DMs realize the impacts of variations in the budget and weights of key concerns on the selected portfolio of projects. 


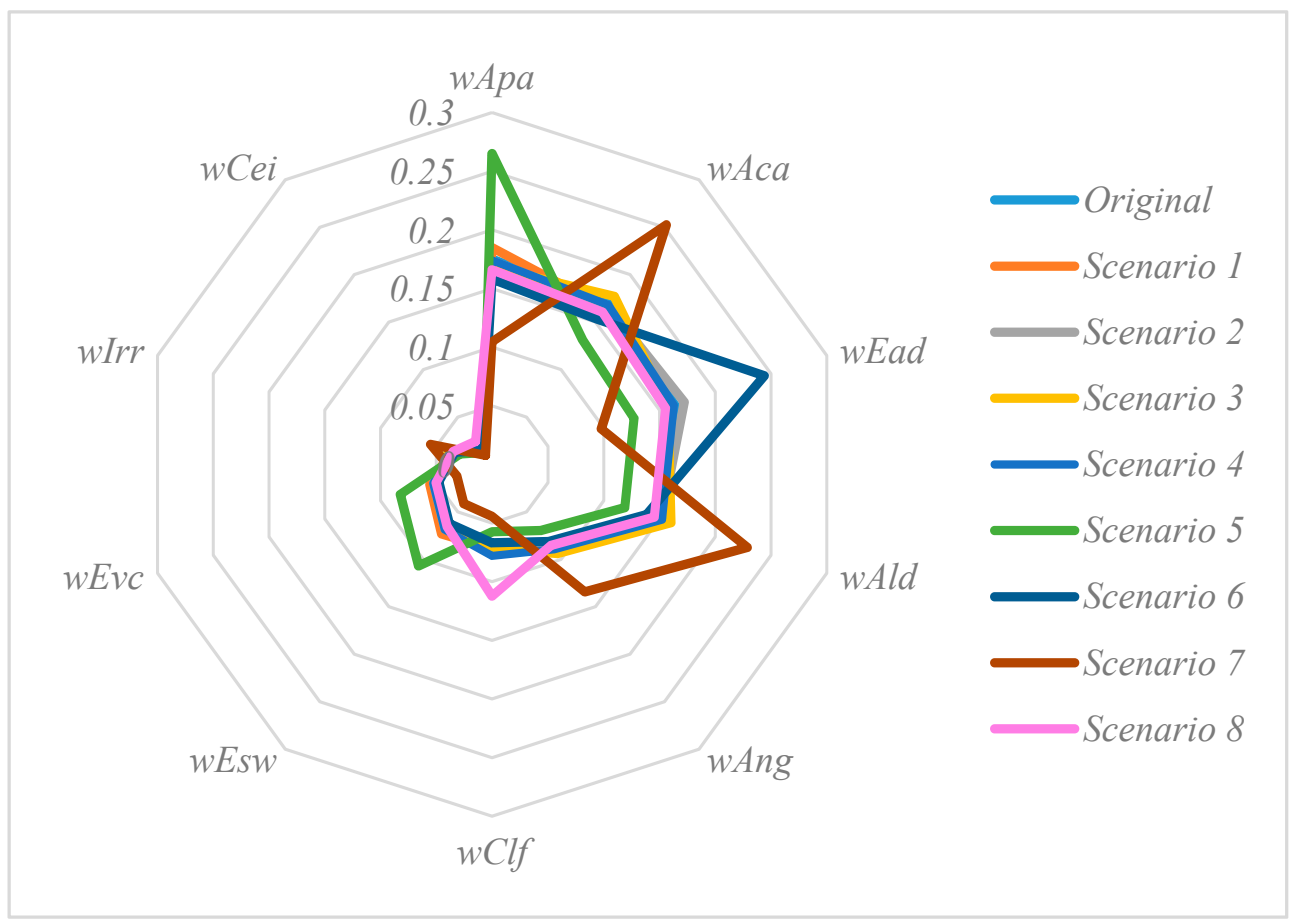

Figure 7. Different scenarios of weights of key concerns.

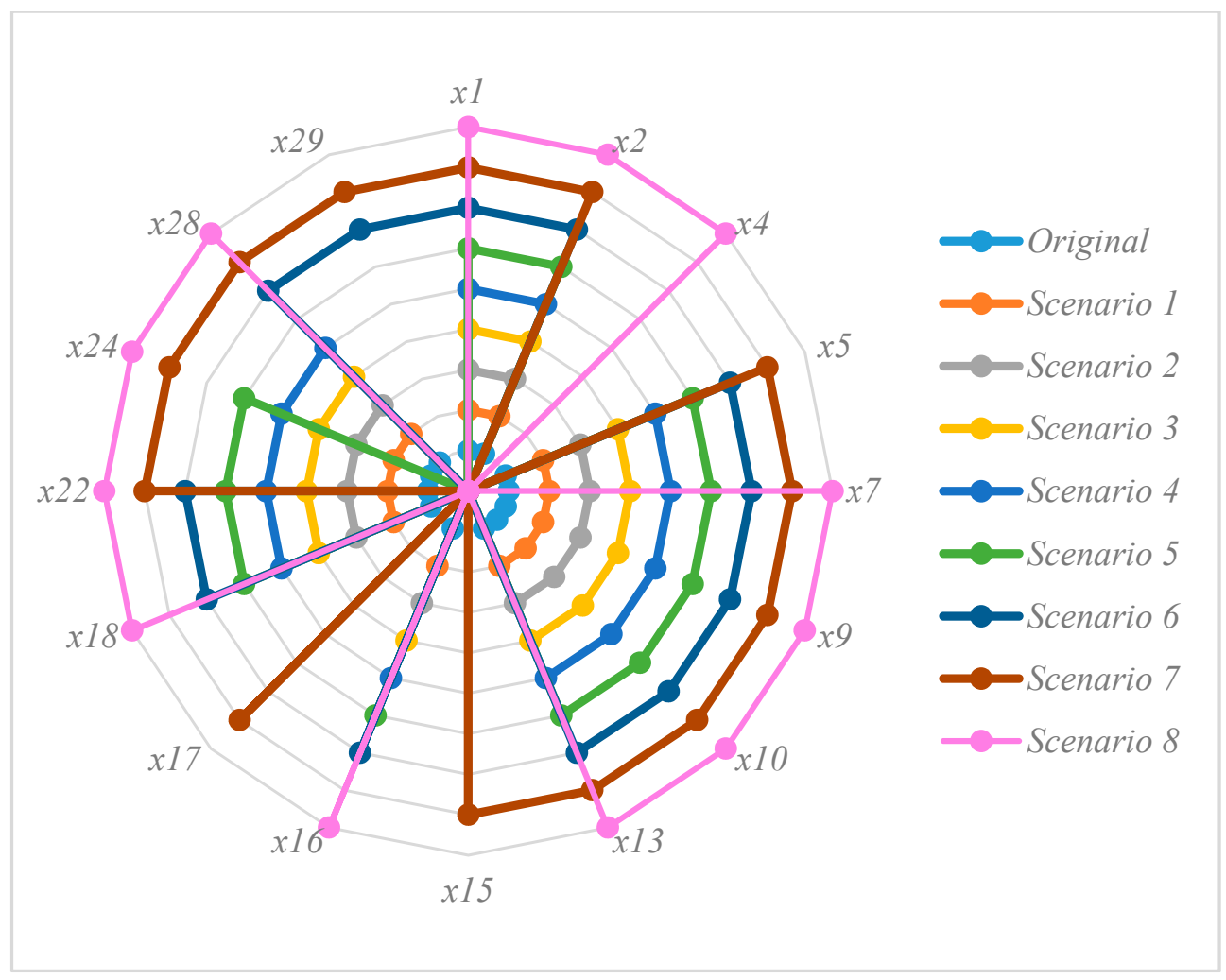

Figure 8. Results of the sensitivity analysis to key concerns weights variation. 


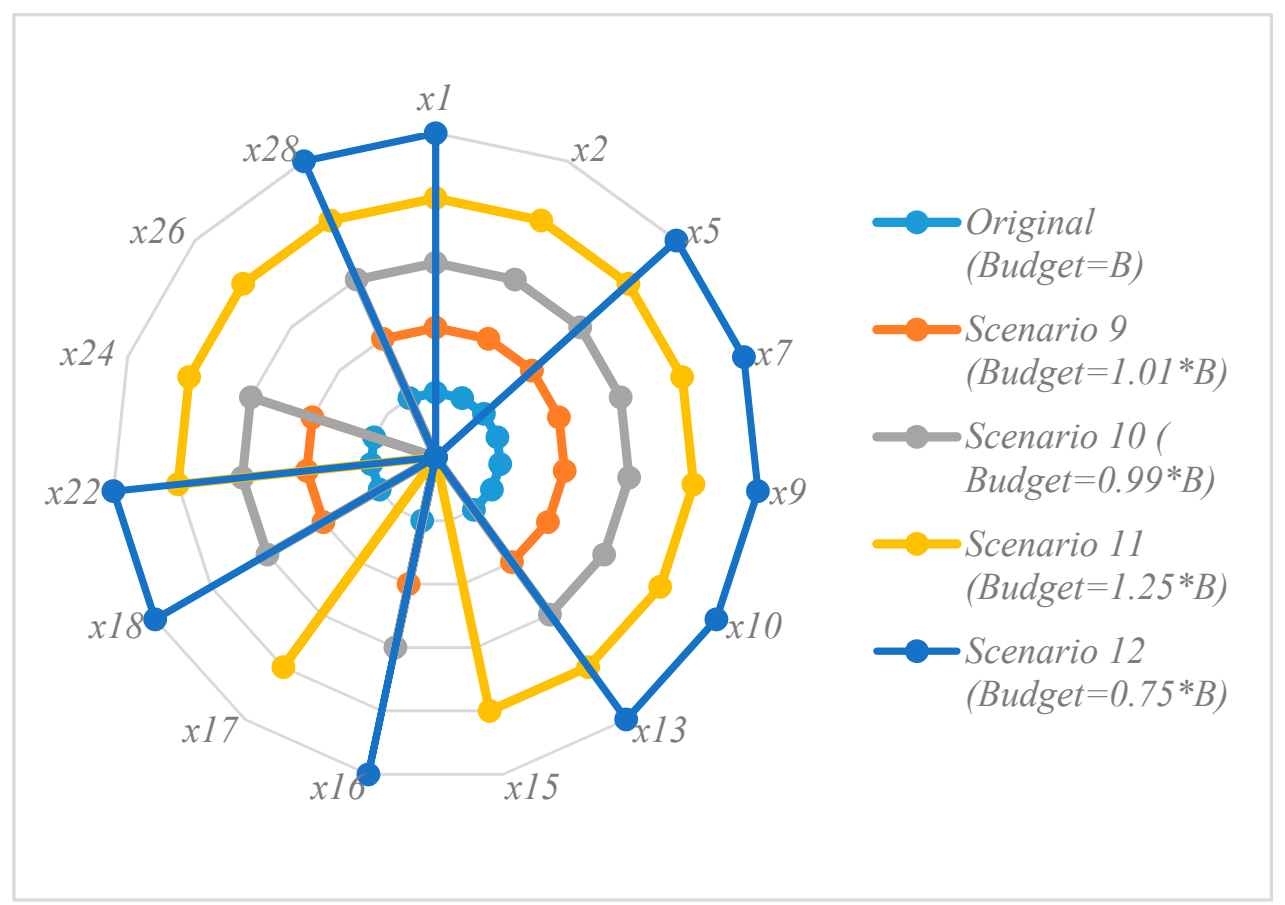

Figure 9. Results of sensitivity to budget variations.

\section{Discussion}

This paper puts forward an integrated approach model for portfolio selection of midstream gas projects to investigate three fundamental characteristics within this decision context: integration of sustainable strategic criteria in the portfolio selection process, consideration of project interdependencies, and adjustment of the ongoing projects.

To the best of the authors' knowledge, no previous study has employed the same approach as that in this paper in the portfolio selection context and has covered the three aforementioned aspects at the same time. However, all of these aspects play influential roles in selecting an appropriate portfolio. In the light of strategic planning, three sustainable strategic areas of concern, including economic, environmental, and social, were recognized. The presented descriptor of performance of key concerns was aligned with the strategic orientation of the organization. According to specifications of the real gas pipeline projects, five types of interdependencies among projects were distinguished: cost, environmental, social, NPV, and technical interdependencies. Using performance descriptions, the performance of each project with respect to each key concern was calculated when the interdependent projects existed in the portfolio. Correct termination of on-going projects was an achievement that would prevent an organization from enormous losses; of note, few research works have addressed this issue so far.

The value concept was employed in the context of the mid-stream gas industry, and MACBETH as an appropriate multi-criteria methodology was utilized to prioritize gas pipeline projects. Using DMs' preferences in qualitative pairwise comparison judgments of the difference in attractiveness, M-MACBETH provided a value curve for each key concern. The proposed model employed an additive value function to compile a portfolio with the highest value regarding the constraints.

A real-world case study in the gas industry was conducted to validate the developed framework's practicability and effectiveness. The results showed that ignoring project interdependency or not considering the project termination issue would reduce the accuracy of the selection and the chance of funding wrong projects would also increase. As seen in the sensitivity analysis, the selected portfolio remains stable under slight variations in the budget and weights of key concerns. However, significant variations may alter the selected projects, making it necessary to modify the selected portfolio. 
From a practical perspective, this research remarked some real characteristics of the project which provide theoretical guidance on the practice of project portfolio selection. The proposed model can be extended and applied to other linear engineering projects such as energy transmission, road, and railway systems. However, due to the process-oriented nature of the framework, caution is required in generalizing the results, and notable aspects of industry and candidate projects must be investigated.

This study generated valuable insights into the project portfolio selection problem. However, there were some research limitations. Project portfolio selection is inherently complex due to bridging the distinction between top management level and operational plans at micro level. Finding the right panel of experts with a systematic and comprehensive view is one of the limitations of this problem. The other limitation of the proposed methodology is the time-consuming process. A heuristic approach is needed in order to mitigate the complexity of the process and the number of pairwise comparisons. Computationally, the proposed portfolio selection model leads to a linear 0-1 programming problem. According to the size of our problem, the model was solved in a reasonable time. Developing heuristic algorithms would be of interest to determine efficient portfolios for large scale instances.

Future research in this line of research ought to address other related real-world features. Additionally, Pairwise project interdependencies are considered sufficient for this research context, while the model could be extended by considering interdependencies between any subset of projects in the other context. Considering uncertainty conditions in the methodology is a part of our longer term aims. Given that natural gas projects are characterized by heavy investments and organizations can provide additional "outside" funding, budget can be a 'soft constraint', which is adjusted to some extent.

Author Contributions: F.L.D. designed the research, developed the model, gathered data through conducting interviews with the experts, implemented the process, obtained, and analyzed the results, and wrote the manuscript. S.H.G. and M.A. contributed to developing the research idea, provided extensive advice throughout the study regarding the methodology, findings, and revised the manuscript. All authors have read and agreed to the published version of the manuscript.

Funding: The work was supported by the Iranian Gas Engineering and Development Company (Contract No 162p).

Acknowledgments: We would like to give our thanks to the staff of the IGEDC, who cooperated for the accomplishment of the interviews and implementing the process. The first author extends thanks to Oliveira and Bana e Costa for their methodological and scientific support during her sabbatical visit to the Centre for Management Studies of Instituto Superior Técnico, Universidade de Lisboa.

Conflicts of Interest: The authors declare no conflict of interest.

\section{Appendix A}

Below, we provide the details of the calculation of NPV for active projects and potential projects in the gas industry in Equations (A1) and (A2), respectively.

$$
\begin{gathered}
N P V_{i}=\left(\sum_{t=0}^{T_{i}}\left(\frac{N C F_{i t}}{(1+r)^{t}}\right)\right) x_{i}+\left(\sum_{t=0}^{T_{i}} \sum_{j=1(j \neq i)}^{n} \frac{N C F_{i j t}}{(1+r)^{t}} x_{j}\right) x_{i}+\left(S V_{i}-R C_{i}\right)\left(1-x_{i}\right), \quad i \in P_{a} . \\
N P V_{i}=\left(\sum_{t=0}^{T_{i}}\left(\frac{N C F_{i t}}{(1+r)^{t}}\right)\right) x_{i}+\left(\sum_{t=0}^{T_{i}} \sum_{j=1(j \neq i)}^{n} \frac{N C F_{i j t}}{(1+r)^{t}} x_{j}\right) x_{i}, \quad i=1,2, \ldots, n \text {. and } i \notin P_{a} .
\end{gathered}
$$

where $N C F_{i t}$ is the net cash flow of project $i$ in the $t$ th year, and $N C F_{i j t}$ is the change in net cash flow of project $i$ in the $t$ th year when the project $j$ is included in the portfolio. In the first and second terms, $r$ stands for the discount rate. $R C_{i}$ in Equation (A1) is the reputation cost of project $i$ if it is given up. 


\section{References}

1. Liu, D.; Zhou, W.; Pan, X. Risk evaluation for city gas transmission and distribution system based on information revision. J. Loss Prev. Process Ind. 2016, 41, 194-201. [CrossRef]

2. Guo, M.; Bu, Y.; Cheng, J.; Jiang, Z. Natural Gas Security in China: A Simulation of Evolutionary Trajectory and Obstacle Degree Analysis. Sustainability 2019, 11, 96. [CrossRef]

3. Khan, M.I. Evaluating the strategies of compressed natural gas industry using an integrated SWOT and MCDM approach. J. Clean. Prod. 2018, 172, 1035-1052. [CrossRef]

4. Balogun, A.; Matori, A.; Lawal, D.U.; Chandio, I. Optimal oil pipeline route selection using GIS: Community participation in weight derivation and disaster mitigation. In Proceedings of the International Conference on Future Environment and Energy, Singapore, 26-28 February 2012; Volume 28, pp. 100-104.

5. Li, M.; Liu, L.; Li, Y.; Xu, Y. Evaluating the Risk of Natural Gas Pipeline Operation Management in Intuitionistic Fuzzy Linguistic Environments. Math. Probl. Eng. 2018. [CrossRef]

6. Hafezi, R.; Akhavan, A.N.; Pakseresht, S. Projecting plausible futures for Iranian oil and gas industries: Analyzing of historical strategies. J. Nat. Gas Sci. Eng. 2017, 39, 15-27. [CrossRef]

7. Sweis, R.; Moarefi, A.; Amiri, M.H.; Moarefi, S.; Saleh, R. Causes of delay in Iranian oil and gas projects: A root cause analysis. Int. J. Energy Sect. Manag. 2019, 13, 630-650. [CrossRef]

8. Castillo, L.; Dorao, C.A. Decision-making in the oil and gas projects based on game theory: Conceptual process design. Energy Convers. Manag. 2013, 66, 48-55. [CrossRef]

9. Ghasemzadeh, F.; Archer, N.P. Project portfolio selection through decision support. Decis. Support Syst. 2000, 29, 73-88. [CrossRef]

10. Li, X.; Wang, Y.; Yan, Q.; Zhao, X. Uncertain mean-variance model for dynamic project portfolio selection problem with divisibility. Fuzzy Optim. Decis. Mak. 2019, 18, 37-56. [CrossRef]

11. Dey, P.K. An integrated assessment model for cross-country pipelines. Environ. Impact Assess. Rev. 2002, 22, 703-721. [CrossRef]

12. Valavanides, M.S. Portfolios as off-equilibrium processes: Similarities and affinities-Towards rational prioritizing and selecting portfolio components. Procedia Soc. Behav. Sci. 2014, 119, 539-548. [CrossRef]

13. Kaiser, M.G.; Arbi, F.E.; Ahlemann, F. Successful project portfolio management beyond project selection techniques: Understanding the role of structural alignment. Int. J. Proj. Manag. 2015, 33, 126-139. [CrossRef]

14. Rad, F.H.; Rowzan, S.M. Designing a hybrid system dynamic model for analyzing the impact of strategic alignment on project portfolio selection. Simul. Model. Pract. Theory 2018, 89, 175-194.

15. Tanriverdi, H. Information technology relatedness, knowledge management capability, and performance of multibusiness firms. MIS Q. 2005, 29, 311-334. [CrossRef]

16. Mild, P.; Liesiö, J.; Salo, A. Selecting infrastructure maintenance projects with Robust Portfolio Modeling. Decis. Support Syst. 2015, 77, 21-30. [CrossRef]

17. Gonçalves, L.R.; Mello, A.M.D.; Nascimento, P.T.S. How different R\&D project types are terminated. In Proceedings of the PICMET'14 Conference: Portland International Center for Management of Engineering and Technology, Infrastructure and Service Integration, Kanazawa, Japan, 27-31 July 2014; IEEE: Piscataway, NJ, USA; pp. 2506-2515.

18. Canbaz, B.; Marle, F. Construction of project portfolio considering efficiency, strategic effectiveness, balance and project interdependencies. Int. J. Proj. Organ. Manag. 2016, 8, 103-126. [CrossRef]

19. Cooper, R.G.; Edgett, S.J.; Kleinschmidt, E.J. New product portfolio management: Practices and performance. J. Prod. Innov. Manag. 1999, 16, 333-351. [CrossRef]

20. Archer, N.; Ghasemzadeh, F. An integrated framework for project portfolio selection. Int. J. Proj. Manag. 1999, 17, 207-216. [CrossRef]

21. Oosthuizen, C.; Grobbelaar, S.S.; Bam, W. Exploring the link between PPM implementation and company success in achieving strategic goals: An empirical framework. S. Afr. J. Ind. Eng. 2016, 27, 238-250. [CrossRef]

22. Wu, Y.; Li, J.; Wang, J.; Huang, Y. Project portfolio management applied to building energy projects management system. Renew. Sustain. Energy Rev. 2012, 16, 718-724. [CrossRef]

23. García-Melón, M.; Poveda-Bautista, R. Using the strategic relative alignment index for the selection of portfolio projects application to a public Venezuelan Power Corporation. Int. J. Prod. Econ. 2015, 170, 54-66. [CrossRef]

24. Wu, Y.; Xu, C.; Ke, Y.; Li, X.; Li, L. Portfolio selection of distributed energy generation projects considering uncertainty and project interaction under different enterprise strategic scenarios. Appl. Energy 2019, 236, 444-464. [CrossRef]

25. Debnath, A.; Roy, J.; Kar, S.; Zavadskas, E.K.; Antucheviciene, J. A hybrid MCDM approach for strategic project portfolio selection of Agro by-products. Sustainability 2017, 9, 1302. [CrossRef]

26. Khalili-Damghani, K.; Tavana, M. A comprehensive framework for sustainable project portfolio selection based on structural equation modeling. Proj. Manag. J. 2014, 45, 83-97. [CrossRef]

27. Tinoco, M.A.; Dutra, C.; Ribeiro, J.L.; Miorando, R.; Caten, C.S. An integrated model for evaluation and optimisation of business project portfolios. Eur. J. Ind. Eng. 2018, 12, 442-463. [CrossRef]

28. Dobrovolskien e, N.; Tamošiuniene, R. Sustainability-Oriented Financial Resource Allocation in a Project Portfolio through Multi-Criteria Decision-Making. Sustainability 2016, 8, 485.

29. Yi, P.; Li, W.; Zhang, D. Assessment of city sustainability using MCDM with interdependent criteria weight. Sustainability 2019, 11, 1632. [CrossRef] 
30. Xu, D.; Lv, L.; Ren, X.; Ren, J.; Dong, L. Route selection for low-carbon ammonia production: A sustainability prioritization framework based-on the combined weights and projection ranking by similarity to referencing vector method. J. Clean. Prod. 2018, 193, 263-276. [CrossRef]

31. Kwast-kotlarek, U.; Hełdak, M. Evaluation of the Construction and Investment Process of a High-Pressure Gas Pipeline with Use of the Trenchless Method and Open Excavation Method. Analytic Hierarchy Process (AHP). Sustainability 2019, 11, 2438. [CrossRef]

32. Lee, J.W.; Kim, S.H. An integrated approach for interdependent information system project selection. Int. J. Proj. Manag. 2001, 19, 111-118. [CrossRef]

33. Bathallath, S.; Smedberg, Å.; Kjellin, H. Managing project interdependencies in IT/IS project portfolios: A review of managerial issues. Int. J. Inf. Syst. Proj. Manag. 2016, 4, 67-82.

34. Thompson, J.D. Organizations in Action: Social Science Bases of Administrative Theory; Transaction Publishers: New Brunswick, NJ, USA, 2003.

35. Santhanam, R.; Kyparisis, G.J. A decision model for interdependent information system project selection. Eur. J. Oper. Res. 1996, 89, 380-399. [CrossRef]

36. Schmidt, R.L. A model for R\&D project selection with combined benefit, outcome and resource interactions. IEEE Trans. Eng. Manag. 1993, 40, 403-410.

37. Eilat, H.; Golany, B.; Shtub, A. Constructing and evaluating balanced portfolios of R\&D projects with interactions: A DEA based methodology. Eur. J. Oper. Res. 2006, 172, 1018-1039.

38. Ghapanchi, A.H.; Tavana, M.; Khakbaz, M.H.; Low, G. A methodology for selecting portfolios of projects with interactions and under uncertainty. Int. J. Proj. Manag. 2012, 30, 791-803. [CrossRef]

39. Dickinson, M.W.; Thornton, A.C.; Graves, S. Technology portfolio management: Optimizing interdependent projects over multiple time periods. IEEE Trans. Eng. Manag. 2001, 48, 518-527. [CrossRef]

40. Stummer, C.; Heidenberger, K. Interactive R\&D portfolio analysis with project interdependencies and time profiles of multiple objectives. IEEE Trans. Eng. Manag. 2003, 50, 175-183.

41. Liesiö, J.; Mild, P.; Salo, A. Robust portfolio modeling with incomplete cost information and project interdependencies. Eur. J. Oper. Res. 2008, 190, 679-695. [CrossRef]

42. Ghasemi, F.; Sari, M.; Yousefi, V.; Falsafi, R.; Tamošaitienè, J. Project Portfolio Risk Identification and Analysis, Considering Project Risk Interactions and Using Bayesian Networks. Sustainability 2018, 10, 1609. [CrossRef]

43. Killen, C.P.; Kjaer, C. Understanding project interdependencies: The role of visual representation, culture and process. Int. J. Proj. Manag. 2012, 30, 554-566. [CrossRef]

44. Meyer, W.G. Early termination of failing projects: Literature review and research framework. In Proceedings of the PMI ${ }^{\circ}$ Research and Education Conference, Limerick, Ireland, 16-18 July 2012; Project Management Institute: Limerick, Munster, Ireland; Newtown Square, PA, USA, 2012.

45. Thornley, C.V.; Crowley, C.A. Developing the capability to terminate IT projects when they can no longer deliver business value: A discussion of key insights from practitioners. Int. J. Manag. Proj. Bus. 2018, 11, 406-431. [CrossRef]

46. Unger, B.N.; Kock, A.; Gemünden, H.G.; Jonas, D. Enforcing strategic fit of project portfolios by project termination: An empirical study on senior management involvement. Int. J. Proj. Manag. 2012, 30, 675-685. [CrossRef]

47. Cooper, R.G.; Edgett, S.J. Overcoming the crunch in resources for new product development. Res. Technol. Manag. 2003, 46, 48-58. [CrossRef]

48. Belarbi, H. Improving Project Portfolio Decision Making in Theory and Practice. In Proceedings of the 24th European Conference on Information Systems (ECIS), Istanbul, Turkey, 12-15 June 2016.

49. Huang, X.; Xiang, L.; Islam, S.M.N. Optimal project adjustment and selection. Econ. Model. 2014, 36, 391-397. [CrossRef]

50. Huang, X.; Su, X.; Zhao, T. Optimal multinational project adjustment and selection with random parameters. Optimization 2014, 63, 1583-1594. [CrossRef]

51. Ferreira, F.A.F.; Spahr, R.W.; Sunderman, M.A. Using multiple criteria decision analysis (MCDA) to assist in estimating residential housing values. Int. J. Strateg. Prop. Manag. 2016, 20, 354-370. [CrossRef]

52. Marques, M.; Neves-silva, R. Decision support for energy savings and emissions trading in industry. J. Clean. Prod. 2015, 88, 105-115. [CrossRef]

53. Lima, A.S.d.; Damiani, J.H.d.S. A proposed method for modeling research and development (R\&D) project prioritization criteria. In Proceedings of the PICMET: Portland International Center for Management of Engineering and Technology, Portland, OR, USA, 2-6 August 2009; IEEE: Piscataway, NJ, USA, 2009; pp. 599-608.

54. Bana e Costa, C.A.; Beinat, E. Model-Structuring in Public Decision-Aiding; Department of Operational Research, London School of Economic and Political Science: London, UK, 2005.

55. Keeney, R.L. Value-Focused Thinking: A Path to Creative Decisionmaking; Harvard University Press: Cambridge, UK, 1992.

56. Hummel, J.M.; Oliveira, M.D.; Bana e Costa, C.A.; IJzerman, M.J. Supporting the Project Portfolio Selection Decision of Research and Development Investments by Means of Multi-Criteria Resource Allocation Modelling. In Multi-Criteria Decision Analysis to Support Healthcare Decisions; Springer: Berlin/Heidelberg, Germany, 2017; pp. 89-103.

57. Kumar, V.; Persaud, A.N.S.; Kumar, T. To terminate or not an ongoing R\&D project: A managerial dilemma. IEEE Trans. Eng. Manag. 1996, 43, 273-284. 
58. Duarte, B.P.M.; Reis, A. Developing a projects evaluation system based on multiple attribute value theory. Comput. Oper. Res. 2006, 33, 1488-1504. [CrossRef]

59. Keeney, R.L.; Raiffa, H.; Meyer, R.F. Decisions with Multiple Objectives: Preferences and Value Trade-Offs; Cambridge University Press: Cambridge, UK, 1993.

60. Balogun, A.-L.; Matori, A.-N.; Hamid-Mosaku, A.I.; Lawal, D.U.; Chandio, I.A. Fuzzy MCDM-based GIS model for subsea oil pipeline route optimization: An integrated approach. Mar. Georesour. Geotechnol. 2017, 35, 961-969. [CrossRef]

61. Antunes, C.H.; Henriques, C.O. Multi-objective optimization and multi-criteria analysis models and methods for problems in the energy sector. In Multiple Criteria Decision Analysis: State of the Art Surveys; Springer: New York, NY, USA, 2016; pp. $1067-1165$.

62. Bogucki, M.; Polonski, M. Risk analysis for high pressure gas pipeline construction schedule. In Proceedings of the IOP Conference Series: Materials Science and Engineering; IOP Publishing: Bristol, UK, 2019; Volume 471, p. 112042.

63. Luo, H.; Xie, Y.; Lv, J. Effectiveness of soil and water conservation associated with a natural gas pipeline construction project in China. L. Degrad. Dev. 2019, 30, 768-776. [CrossRef]

64. Krishna, P.; Moynihan, K.; Callon, D. Environmental Management Process for Major Projects. In Proceedings of the International Petroleum Technology Conference, Doha, Qatar, 7-9 December 2009.

65. Chen, C.; Li, C.; Reniers, G.; Yang, F. Safety and security of oil and gas pipeline transportation: A systematic analysis of research trends and future needs using WoS. J. Clean. Prod. 2021, 279, 123583. [CrossRef]

66. Zhang, P.; Qin, G.; Wang, Y. Optimal Maintenance Decision Method for Urban Gas Pipelines Based on as Low as Reasonably Practicable Principle. Sustainability 2019, 11, 153. [CrossRef]

67. Dey, P.K. Analytic hierarchy process helps evaluate project in Indian oil pipelines industry. Int. J. Oper. Prod. Manag. 2004, 24, 588-604. [CrossRef]

68. Lopes, Y.G.; de Almeida, A.T. Assessment of synergies for selecting a project portfolio in the petroleum industry based on a multi-attribute utility function. J. Pet. Sci. Eng. 2015, 126, 131-140. [CrossRef]

69. Park, C.Y.; Han, S.H.; Lee, K.-W.; Lee, Y.M. Analyzing Drivers of Conflict in Energy Infrastructure Projects: Empirical Case Study of Natural Gas Pipeline Sectors. Sustainability 2017, 9, 2031. [CrossRef]

70. Carazo, A.F.; Gómez, T.; Molina, J.; Hernández-Díaz, A.G.; Guerrero, F.M.; Caballero, R. Solving a comprehensive model for multiobjective project portfolio selection. Comput. Oper. Res. 2010, 37, 630-639. [CrossRef]

71. Hassanzadeh, F.; Nemati, H.; Sun, M. Robust optimization for interactive multiobjective programming with imprecise information applied to R\&D project portfolio selection. Eur. J. Oper. Res. 2014, 238, 41-53.

72. e Costa, C.A.B.; De Corte, J.-M.; Vansnick, J.-C. MACBETH. Int. J. Inf. Technol. Decis. Mak. 2012, 11, 359-387. [CrossRef]

73. Gürbüz, T.; Albayrak, Y.E. An engineering approach to human resources performance evaluation: Hybrid MCDM application with interactions. Appl. Soft Comput. J. 2014, 21, 365-375. [CrossRef]

74. Carnero, M.C.; Gómez, A. A multicriteria model for optimization of maintenance in thermal energy production systems in hospitals: A case study in a Spanish hospital. Sustainability 2017, 9, 493. [CrossRef]

75. Carnero, M.C.; Gómez, A. Optimization of Decision Making in the Supply of Medicinal Gases Used in Health Care. Sustainability 2019, 11, 2952. [CrossRef]

76. Hurson, C.; Mastorakis, K.; Siskos, Y. Application of a synergy of MACBETH and MAUT multicriteria methods to portfolio selection in Athens stock exchange. Int. J. Multicriteria Decis. Mak. 2012, 2, 113-127. [CrossRef]

77. Carnero, M.C.; Gómez, A. Maintenance strategy selection in electric power distribution systems. Energy 2017, 129, 255-272. [CrossRef]

78. Costa, C.A.B.e.; Oliveira, M.D. A multicriteria decision analysis model for faculty evaluation. Omega 2012, 40, 424-436. [CrossRef]

79. Komchornrit, K. The selection of dry port location by a hybrid CFA-MACBETH-PROMETHEE method: A case study of Southern Thailand. Asian J. Shipp. Logist. 2017, 33, 141-153. [CrossRef]

80. Santhanam, R.; Kyparisis, J. A multiple criteria decision model for information system project selection. Comput. Oper. Res. 1995, 22, 807-818. [CrossRef] 